\author{
Military Technical College \\ Kobry El-Kobbah, \\ Cairo, Egypt
}

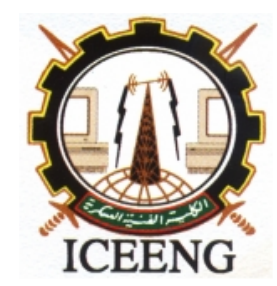

\title{
Photovoltaic Power System Simulation for Micro - Grid Distribution Generation
}

\author{
By
}

Adel El Shahat*

\section{Abstract:}

This paper proposes modeling and simulation of PV Micro - Grid Distribution Generation System for Smart Grid Applications. Because, Distributed Generation (DG) offers great potential in meeting future global energy needs. PV module modeling and inverter technique reviews are presented in this paper. The mathematical PV module modeling depends on Schott ASE-300-DGF PV panel with the aid of MATLAB environment. DC / AC Inverter, Three - phase Inverters, Basic Operation of PWM Inverter, Square - wave operations of DC/AC inverter, Single - phase and Full - Bridge Converters, Three - phase Converters and some MATLAB Inverters Results are introduced. Then, it proposes a PV module when coupled to a load through DC-DC Converter to supply this resistive load with the maximum power from the PV module. Some of DC-DC converters topologies are discussed in brief with concentration on Cúk and SEPIC Converters operations. After that, the mechanism of load matching is described to give the required converter duty cycle at maximum power point (MPP). Relations in 3D figures are introduced for the most probable situations for irradiance and temperature with the corresponding PV voltage and current. Also, 3D figures for the desired duty cycle, output voltage and current of DC-DC converter to gain the maximum power to the resistive load at various irradiance and temperature values.

Keywords: Smart Grid, Distributed generation, Maximum Power, Inverter, DC-DC Converter, PV Module, Modeling, and MATLAB 
* Faculty of Petroleum \& Mining Engineering, Suez Canal University, Egypt

\section{Introduction:}

Of late, the interest in Smart Grid Systems (SGS) is increasing. Photovoltaic systems have become increasingly popular and are ideally suited for distributed generations in smart grid. Because of strict environmental regulations, the lack of corridors for building high voltage transmission systems and security issues, larger power plants have become uneconomical in many regions. Additionally, recent technological advances in small generators, power electronics, and energy storage devices have provided a new opportunity for distributed energy resources that are located closer to loads. Many governments have provided the much needed incentives to promote the utilization of renewable energies, encouraging a more decentralized approach to power delivery systems. In spite of their relatively high cost, there has been very remarkable growth in installed Photovoltaic systems. Recent studies show an exponential increase in the worldwide installed photovoltaic power capacity. There is ongoing research aimed at reducing the cost and achieving higher efficiency. Furthermore, new regulatory laws mandating the use of renewable energy have expanded this market around the world. Currently, photovoltaic generation systems are actively being promoted in order to mitigate environmental issues such as the green house effect and air pollution. Solar energy is the world's major renewable energy source and is available everywhere in different quantities. Photovoltaic panels do not have any moving parts, operate silently and generate no emissions. Another advantage is that solar technology is highly modular and can be easily scaled to provide the required power for different loads [1], [2], [18]. Modeling is a very important part of any engineering practice. Nowadays with the use of computers and powerful software extremely complex systems can be simulated and their performance can be predicted and monitored. A typical photovoltaic system may consist of the solar generator itself and other components that maybe any one of the following: storage elements (especially in stand-alone systems); the utility grid; power converters (DC/DC or Inverters) and associated control circuitry. Availability of models of all these components (especially for the photovoltaic generator itself) at all stages in system development is very important in system sizing, cost analysis and monitoring. Moreover, such models may be tested together with other distributed system models in order to evaluate and predict the overall system performance [19], [1], [2], [20 - 22]. A significant amount of fuel cell research focuses on fundamental issues of performance and cost [3 - 6]. Since the power harvested from the photovoltaic module is different at various operating points it is important that maximum power is obtained from the photovoltaic module [7- 10]. In addition, recent technological advances in small generators, Power Electronics, Smart Metering, Mechatronics and energy storage 
devices have provided a new opportunity for distributed energy resources at the distribution level [23-26]. This paper' calculations are based on practical PV module data in reference [11]. Figure 1 introduces the main components of one - line Diagram of PV and Wind Power Micro - Grid Distribution Generation System.

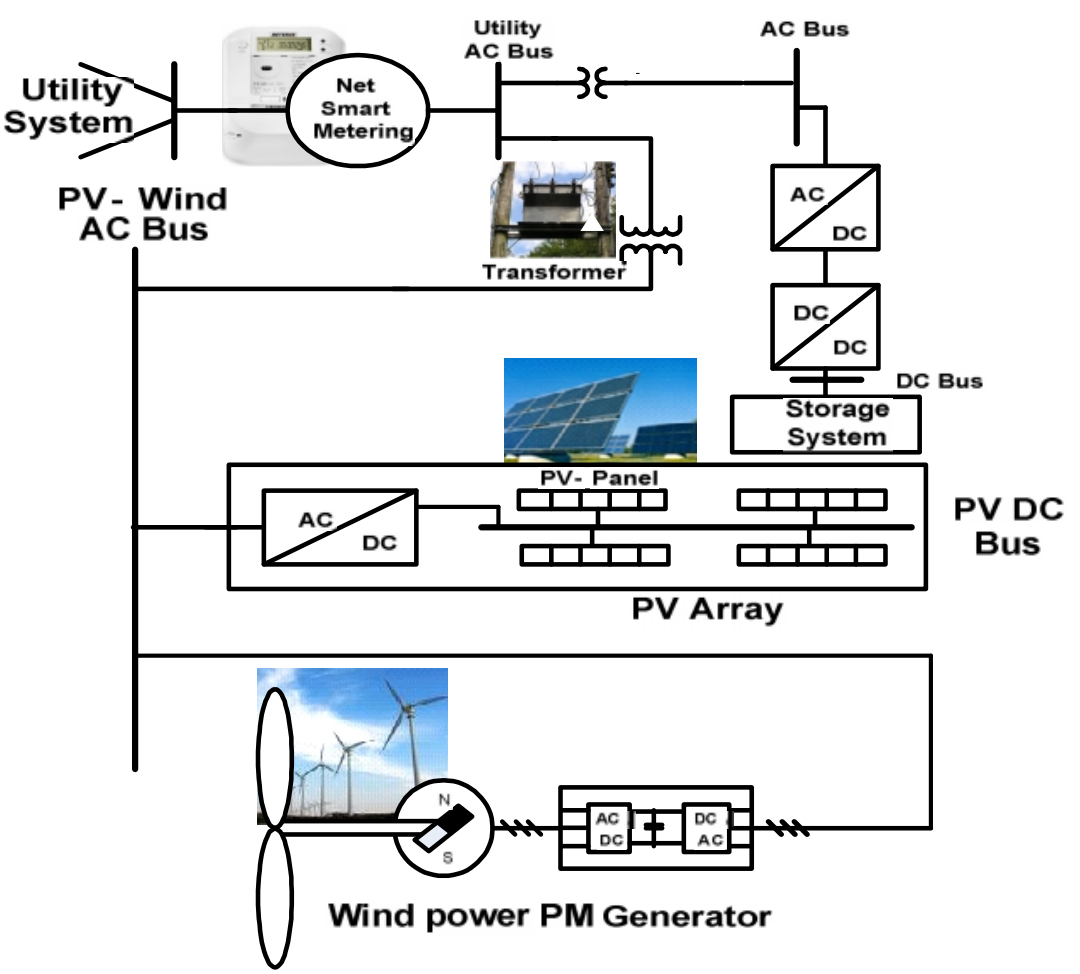

Figure (1) One - line Diagram of PV and Wind Power Micro - Grid Distribution

Generation System

A PV array is usually oversized to compensate for a low power yield during winter months. This mismatching between a PV module and a load requires further over-sizing of the PV array and thus increases the overall system cost. To mitigate this problem, a maximum power point tracker (MPPT) can be used to maintain the PV module's operating point at the MPP. MPPTs can extract more than $97 \%$ of the PV power when properly optimized. A typical photovoltaic system may consist of the solar generator itself and other components that maybe any one of the following: storage elements (especially in stand-alone systems); the utility grid; power converters (DC/DC or Inverters) and associated control circuitry [27-33]. DC-DC converters are electronic devices that are used whenever we want to change DC electrical power efficiently from one voltage level to another. In all applications, we want to perform the conversion with the highest possible efficiency. DC-DC Converters are needed because unlike AC, DC can't simply be stepped up or down using a transformer. In many ways, a DC-DC converter is the DC equivalent of a transformer. They essentially just change the input energy into a different impedance level. So whatever the output voltage level, the output 
power all comes from the input; there's no energy manufactured inside the converter. Quite the contrary, in fact some is inevitably used up by the converter circuitry and components, in doing their job. The Boost converter is another simple power electronic converter and basically consists of a voltage source, an inductor, a power electronic switch (usually a MOS-FET or an IGBT) and a diode. It usually also has a filter capacitor to smoothen the output. Buck converters provide longer battery life for mobile systems that spend most of their time in "stand-by". Buck regulators are often used as switch-mode power supplies for baseband digital core and the power amplifier [34-39]. This paper proposes to the part of DC-DC Converter coupled with resistive load and supplying it with Maximum Power as shown in figure 2, which presents Simple Distributed Generation System with PV Generating Station.

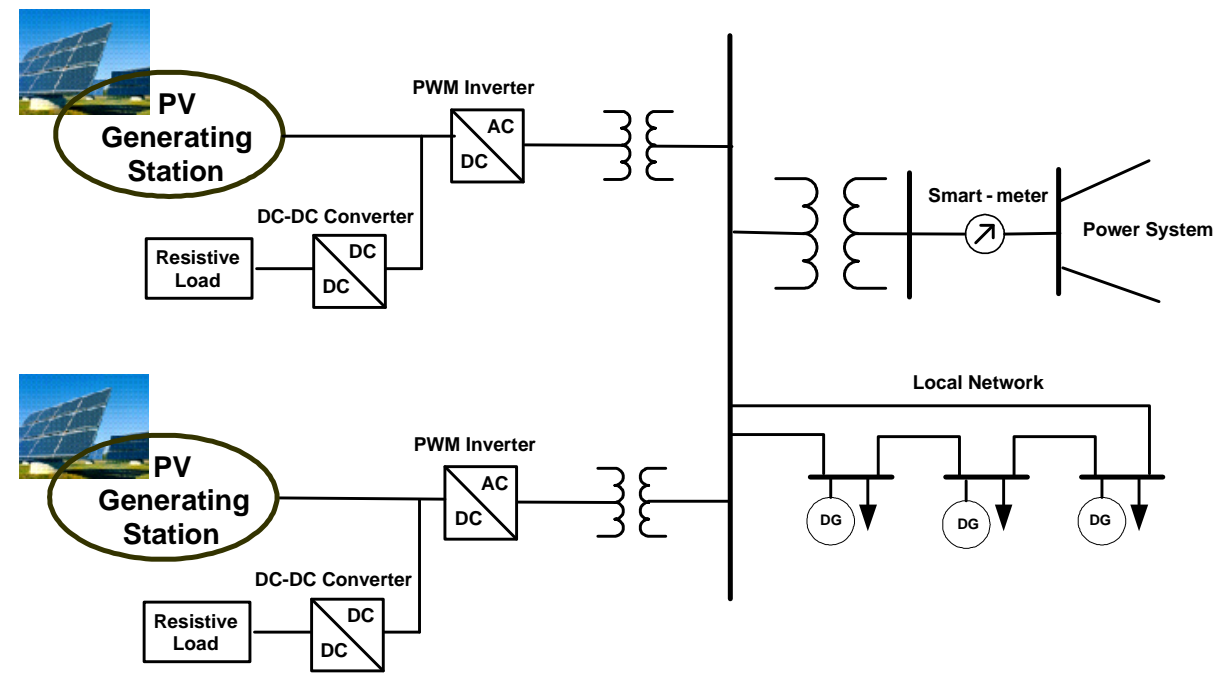

Figure (2) Simple Distributed Generation System with PV Generating Station

\section{PV Cell Model}

The use of equivalent electric circuits makes it possible to model characteristics of a PV cell. The method used here is implemented in MATLAB programs for simulations. The same modeling technique is also applicable for modeling a PV module. There are two key parameters frequently used to characterize a PV cell. Shorting together the terminals of the cell, the photon generated current will follow out of the cell as a short-circuit current $\left(I_{s c}\right)$. Thus, $I_{p h}=I_{s c}$, when there is no connection to the PV cell (open-circuit), the photon generated current is shunted internally by the intrinsic $\mathrm{p}-\mathrm{n}$ junction diode. This gives the open circuit voltage $\left(\mathrm{V}_{\mathrm{oc}}\right)$. The $\mathrm{PV}$ module or cell manufacturers usually provide the values of these parameters in their datasheets [11]. The ASE-300-DGF/50 is an industrial-grade solar power module built to the highest standards. Extremely powerful and reliable, the module delivers maximum performance in large systems that require higher voltages, including the most challenging conditions of military, utility and 
commercial installations. For superior performance, quality and peace of mind, the ASE$300-\mathrm{DGF} / 50$ is renowned as the first choice among those who recognize that not all solar modules are created equal [11]. The simplest model of a PV cell equivalent circuit consists of an ideal current source in parallel with an ideal diode. The current source represents the current generated by photons (often denoted as $I_{p h}$ or $I_{L}$ ), and its output is constant under constant temperature and constant incident radiation of light. The PV panel is usually represented by the single exponential model or the double exponential model. The single exponential model is shown in fig. 3 . The current is expressed in terms of voltage, current and temperature as shown in equation 1 [12].

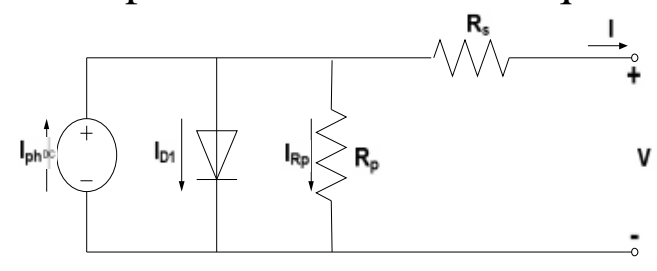

Figure (3) Single exponential model of a PV Cell

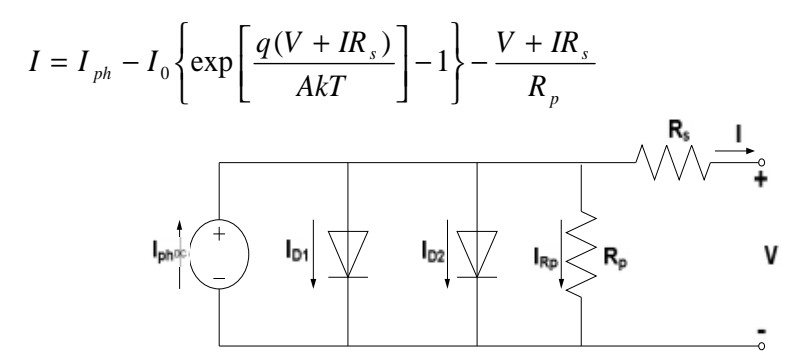

Figure (4) Double exponential model of PV Cell

$$
I=I_{p h}-I_{s_{1}}\left\{\exp \left[\frac{q\left(V+I R_{s}\right)}{A k T}\right]-1\right\}-I_{s_{2}}\left\{\exp \left[\frac{q\left(V+I R_{s}\right)}{A k T}\right]-1\right\}-\frac{V+I R_{s}}{R_{p}}
$$

Where $I_{p h}$ : the photo generated current; $I_{0}$ : the dark saturation current; $I_{s 1}$ : saturation current due to diffusion; $I_{\mathrm{s} 2}$ : is the saturation current due to recombination in the space charge layer; $I_{R p}$ : current flowing in the shunt resistance; $R_{s}$ : cell series resistance; $R_{p}$ : the cell (shunt) resistance; A: the diode quality factor; q: the electronic charge, $1.6 \times 10$ ${ }^{-19} \mathrm{C}$; $\mathrm{k}$ : the Boltzmann's constant, $1.38 \times 10^{-23} \mathrm{~J} / \mathrm{K}$; and $\mathrm{T}$ : the ambient temperature, in Kelvin.

Eq. 1 and Eq. 2 are both nonlinear. Furthermore, the parameters $\left(\mathrm{I}_{\mathrm{ph}}, \mathrm{I}_{\mathrm{s} 1}, \mathrm{I}_{\mathrm{s} 2}, \mathrm{R}_{\mathrm{s}}, \mathrm{R}_{\mathrm{sh}}\right.$ and $\left.\mathrm{A}\right)$ vary with temperature, irradiance and depend on manufacturing tolerance. Numerical methods and curve fitting can be used to estimate [12], [13].

There are three key operating points on the IV curve of a photovoltaic cell. They are the short circuit point, maximum power point and the open circuit point. At the open - 
circuit point on the IV curve, $\mathrm{V}=\mathrm{V}_{\mathrm{oc}}$ and $\mathrm{I}=0$. After substituting these values in the single exponential equation (1) the equation can be obtained [12].

$$
0=I_{p h}-I_{o}\left\{\exp \left[\frac{q V_{o c}}{A k T}\right]-1\right\}-\frac{V_{o c}}{R_{p}}
$$

At the short - circuit point on the IV curve, $I=I_{s c}$ and $V=0$. Similarly, using equation (1), we can obtain.

$$
I_{s c}=I_{p h}-I_{o}\left\{\exp \left[\frac{q I_{s c} R_{s}}{A k T}\right]-1\right\}-\frac{I_{s c} R_{s}}{R_{p}}
$$

At the maximum - power point of the IV curve, we have $\mathrm{I}=\mathrm{I}_{\mathrm{mpp}}$ and $\mathrm{V}=\mathrm{V}_{\mathrm{mpp}}$. We can use these values to obtain the following:

$$
I_{m p p}=I_{p h}-I_{o}\left\{\exp \left[\frac{q\left(V_{m p p}+I_{m p p} R_{s}\right)}{A k T}\right]-1\right\}-\frac{V_{m p p}+I_{m p p} R_{s}}{R_{p}}
$$

The power transferred to the load can be expressed as

$$
\mathrm{P}=\mathrm{IV}
$$

We can estimate the diode quality factor as:

And

$$
A=\frac{V_{m p p}+I_{m p p} R_{s o}-V_{o c}}{V_{T}\left\{\ln \left(I_{s c}-\frac{V_{m p p}}{R_{s h o}}-I_{m p p}\right)-\ln \left(I_{s c}-\frac{V_{o c}}{R_{o}}\right)+\frac{I_{m p p}}{I_{s c}-\left(V_{o c} / R_{s o}\right)}\right\}}
$$

$$
\begin{gathered}
\mathrm{R}_{\mathrm{p}}=\mathrm{R}_{\mathrm{sho}} \\
I_{o}=\left(I_{s c}-\frac{V_{o c}}{R_{p}}\right) \cdot \exp \left(-\frac{V_{o c}}{A V_{T}}\right) \\
R_{s}=R_{s o}-\frac{A V_{T}}{I_{o}} \cdot \exp \left(-\frac{V_{o c}}{A V_{T}}\right) \\
I_{p h}=I_{s c}\left(1+\frac{R_{s}}{R_{p}}\right)+I_{o}\left(\exp \frac{I_{s c} R_{s}}{A V_{T}}-1\right)
\end{gathered}
$$

As a very good approximation, the photon generated current, which is equal to $I_{s c}$, is directly proportional to the irradiance, the intensity of illumination, to PV cell [14]. Thus, if the value, $I_{s c}$, is known from the datasheet, under the standard test condition, $G_{o}=1000 \mathrm{~W} / \mathrm{m}^{2}$ at the air mass $(A M)=1.5$, then the photon generated current at any other irradiance, $G(\mathrm{~W} / m 2)$, is given by:

$$
I_{s c \mid G}=\left(\frac{G}{G_{0}}\right) I_{s c \mid G 0}
$$

It should be notified that, in a practical PV cell, there is a series of resistance in a current path through the semiconductor material, the metal grid, contacts, and current collecting bus [15]. These resistive losses are lumped together as a series resister $\left(R_{s}\right)$. Its effect becomes very conspicuous in a PV module that consists of many series-connected cells, and the value of resistance is multiplied by the number of cells. Shunt resistance is a loss associated with a small leakage of current through a resistive path in parallel with the intrinsic device [15]. This can be represented by a parallel resister $\left(R_{p}\right)$. Its effect is 
much less conspicuous in a PV module compared to the series resistance so it may be ignored [15], [16]. The ideality factor denoted as $A$ and takes the value between one and two (as to reach the nominated characteristics) [16].

\section{Photovoltaic Module Modeling}

A single PV cell produces an output voltage less than $1 \mathrm{~V}$, thus a number of PV cells are connected in series to achieve a desired output voltage. When series-connected cells are placed in a frame, it is called as a module. When the PV cells are wired together in series, the current output is the same as the single cell, but the voltage output is the sum of each cell voltage. Also, multiple modules can be wired together in series or parallel to deliver the voltage and current level needed. The group of modules is called an array. The panel construction provides protection for individual cells from water, dust etc, as the solar cells are placed into an encapsulation of flat glass. Our case here depicts a typical connection of 216 cells that are connected in series [11]. The strategy of modelling a PV module is no different from modelling a PV cell. It uses the same PV cell model. The parameters are the all same, but only a voltage parameter (such as the open-circuit voltage) is different and must be divided by the number of cells. An electric model with moderate complexity [17] is shown in figure 5, and provides fairly accurate results. The model consists of a current source $\left(I_{s c}\right)$, a diode $(D)$, and a series resistance $\left(R_{s}\right)$. The effect of parallel resistance $\left(R_{p}\right)$ is very small in a single module, thus the model does not include it. To make a better model, it also includes temperature effects on the short-circuit current $\left(I_{s c}\right)$ and the reverse saturation current of diode $\left(I_{o}\right)$. It uses a single diode with the diode ideality factor set to achieve the best $I-V$ curve match.

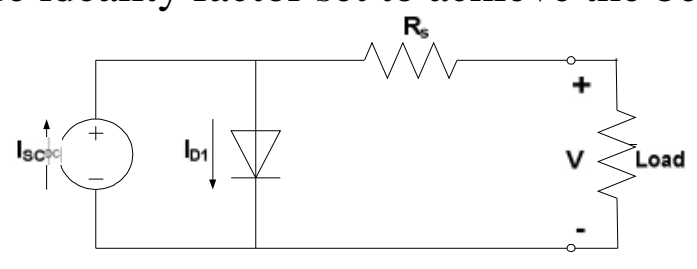

Figure (5) Equivalent circuit used in the simulations

The equation (13) describes the current-voltage relationship of the PV cell.

$$
I=I_{s c}-I_{o}\left(\exp \left(q\left(\frac{V+I R_{s}}{A k T}\right)\right)-1\right)
$$

Where: $\mathrm{I}$ is the cell current (the same as the module current); $\mathrm{V}$ is the cell voltage = \{module voltage $\} \div\{$ No. of cells in series $\} ; \mathrm{T}$ is the cell temperature in Kelvin (K).

First, calculate the short-circuit current $\left(I_{s c}\right)$ at a given cell temperature $(T)$ :

$$
I_{s c \mid T}=I_{s c \mid T}\left[1+a\left(T-T_{r e f}\right)\right]
$$


Where: $I_{s c}$ at $T_{r e f}$ is given in the datasheet (measured under irradiance of $1000 \mathrm{~W} / \mathrm{m}^{2}$ ), $T_{\text {ref }}$ is the reference temperature of PV cell in Kelvin $(K)$, usually $298 K\left(25^{\circ} \mathrm{C}\right), a$ is the temperature coefficient of $I_{s c}$ in percent change per degree temperature also given in the datasheet.

The short-circuit current $\left(I_{s c}\right)$ is proportional to the intensity of irradiance, thus $I_{s c}$ at a given irradiance $(G)$ is introduced by Eq. 12.

The reverse saturation current of diode $\left(I_{o}\right)$ at the reference temperature $\left(T_{r e f}\right)$ is given by the equation (15) with the diode ideality factor added:

$$
I_{0}=\frac{I_{s c}}{\left(\exp \left(\frac{q V o c}{A k T}\right)-1\right)}
$$

The reverse saturation current $\left(I_{o}\right)$ is temperature dependant and the $I_{o}$ at a given temperature $(T)$ is calculated by the following equation [17].

$$
I_{0 \mid T}=I_{0 \mid T_{r f}}\left(\frac{T}{T_{r e f}}\right)^{\frac{3}{A}} \exp \left(\frac{-q E_{g}}{A k}\left(\frac{1}{T_{r e f}}-\frac{1}{T_{r e f}}\right)\right)
$$

The diode ideality factor $(A)$ is unknown and must be estimated. It takes a value between one and two; however, the more accurate value is estimated by curve fitting [17] also, it can be estimated by try and error until accurate value achieved. $\mathrm{E}_{\mathrm{g}}$ is the Band gap energy (1.12 V (Si); $1.42(\mathrm{GaAs}) ; 1.5(\mathrm{CdTe}) ; 1.75$ (amorphous $\mathrm{Si})$ ).

The series resistance $\left(R_{s}\right)$ of the PV module has a large impact on the slope of the $I-V$ curve near the open-circuit voltage $\left(V_{o c}\right)$, hence the value of $R_{s}$ is calculated by evaluating the slope $d I / d V$ of the $I-V$ curve at the $V_{o c}$ [17]. The equation for $R_{s}$ is derived by differentiating the I-V equation and then rearranging it in terms of $R_{s}$ as introduced in equation (17).

$$
R_{s}=-\left.\frac{d V}{d I}\right|_{V o c}-\frac{A k T / q}{I_{0} \exp \left(\frac{q V_{o c}}{A k T}\right)}
$$

Where: $\left.\frac{d V}{d I}\right|_{V_{\alpha}}$ is the slope of the $I-V$ curve at the $\mathrm{V}_{\mathrm{oc}}$ (using the I-V curve in the datasheet then divide it by the number of cells in series); $\mathrm{V}_{\mathrm{oc}}$ is the open-circuit voltage of cell (Dividing $\mathrm{V}_{\mathrm{oc}}$ in the datasheet by the number of cells in series).

Finally, the equation of $I-V$ characteristics is solved using the Newton's method for rapid convergence of the answer, because the solution of current is recursive by inclusion of a series resistance in the model [17]. The Newton's method is described as:

$$
x_{n+1}=x_{n}-\frac{f\left(x_{n}\right)}{f^{\prime}\left(x_{n}\right)}
$$

Where: $f^{\prime}(x)$ is the derivative of the function, $f(x)=0, x_{n}$ is a present value, and $x_{n+1}$ is a next value.

$$
f(I)=I_{s c}-I-I_{o}\left(\exp \left(q\left(\frac{V+I R_{s}}{A k T}\right)\right)-1\right)=0
$$

By using the above equations the following output current $(I)$ is computed iteratively. 


$$
I_{n+1}=I_{n}-\frac{I_{s c}-I_{n}-I_{o}\left(\exp \left(q\left(\frac{V+I_{n} R_{s}}{A k T}\right)\right)-1\right)}{-1-I_{o}\left(\frac{q R_{s}}{A k T}\right) \exp \left(q\left(\frac{V+I_{n} R_{s}}{A k T}\right)\right)}
$$

The figures of $I-V$ characteristics at various module temperatures are simulated with the MATLAB model for our PV module are shown. Also, the $P-V$ relations at various module temperatures are presented. All of these are done at various irradiance values are introduced.

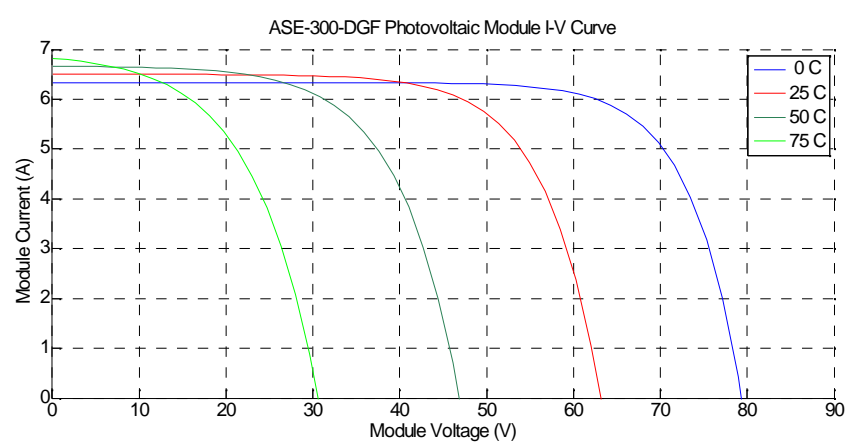

Figure (6) $I$-V curves at $\left(1 \mathrm{KW} / \mathrm{m}^{2} ; 0,25,50,75^{\circ} \mathrm{C}\right)$

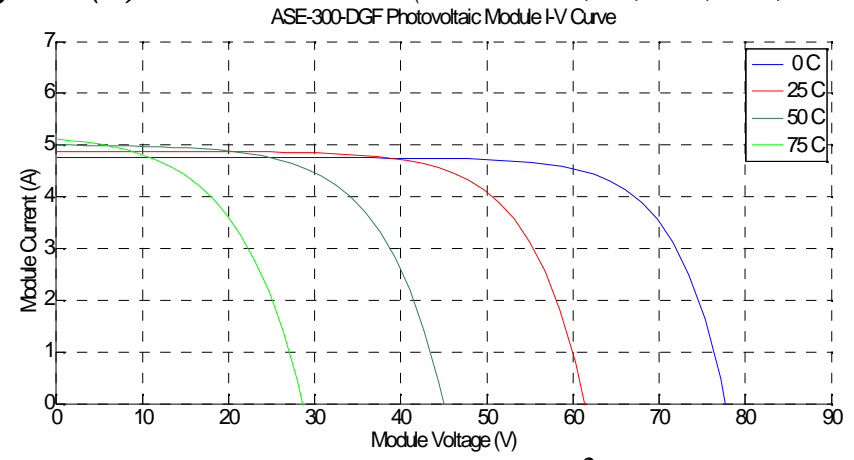

Figure (7) $I$-V curves $\left(0.75 \mathrm{KW} / \mathrm{m}^{2} ; 0,25,50,75^{\circ} \mathrm{C}\right)$

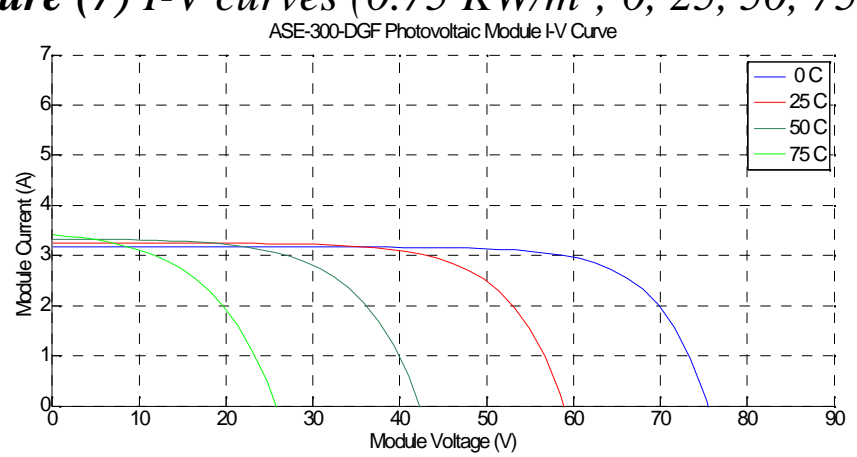

Figure (8) I-V curves $\left(0.50 \mathrm{KW} / \mathrm{m}^{2} ; 0,25,50,75^{\circ} \mathrm{C}\right)$ 


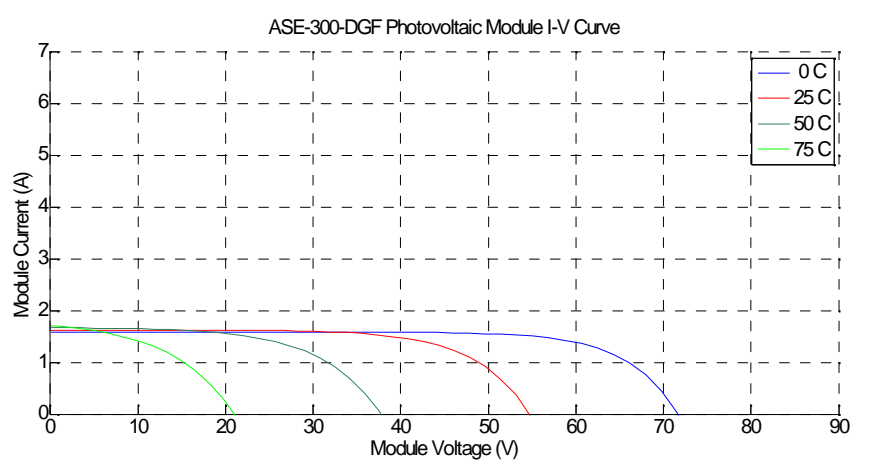

Figure (9) $I$-V curves $\left(0.25 \mathrm{KW} / \mathrm{m}^{2} ; 0,25,50,75^{\circ} \mathrm{C}\right)$

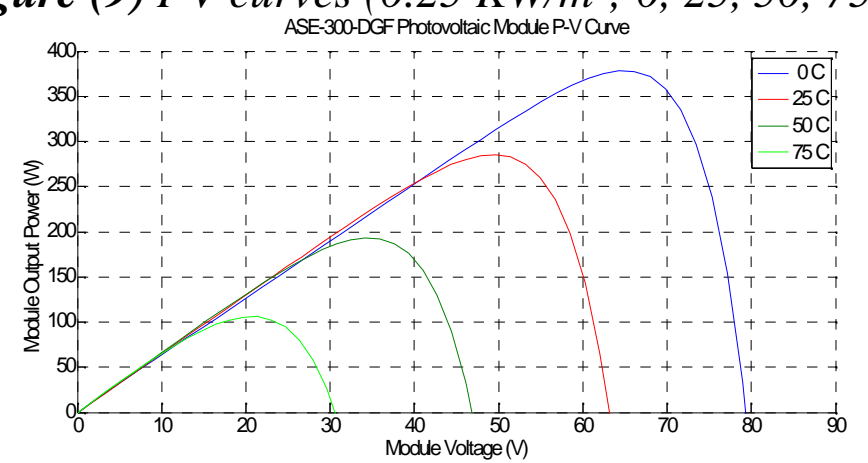

Figure (10) $P-V$ curves at $\left(1 \mathrm{KW} / \mathrm{m}^{2} ; 0,25,50,75^{\circ} \mathrm{C}\right)$

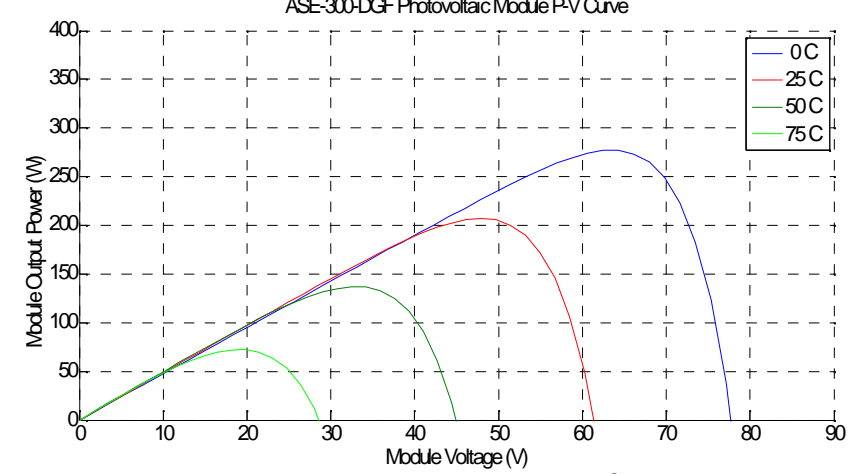

Figure (11) $P$-V curves $\left(0.75 \mathrm{KW} / \mathrm{m}^{2} ; 0,25,50,75^{\circ} \mathrm{C}\right)$

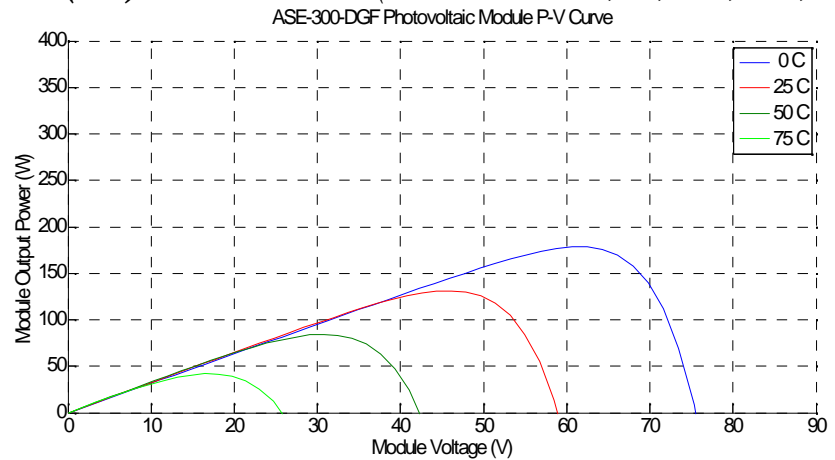

Figure (12) P-V curves $\left(0.50 \mathrm{KW} / \mathrm{m}^{2} ; 0,25,50,75^{\circ} \mathrm{C}\right)$ 


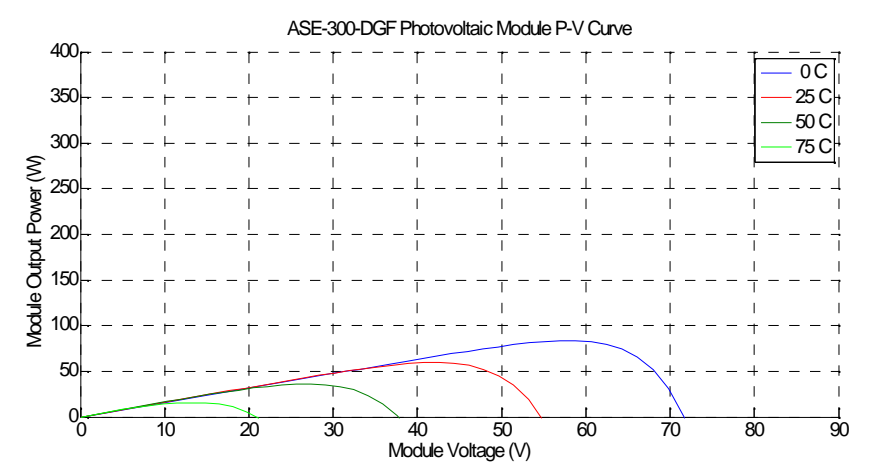

Figure (13) $P$-V curves $\left(0.25 \mathrm{KW} / \mathrm{m}^{2} ; 0,25,50,75^{\circ} \mathrm{C}\right)$

\section{DC / AC Inverters}

For energy processing of PV and wind power, control DC / AC inverters are needed. We are interested in micro grid distribution generation to process $\mathrm{PV}$ and wind power in order of a few MW. A three - phase inverter has three - legs, one for each phase, as shown in figure 13. Each inverter leg operates as a single - phase inverter. The output voltage of each leg $\mathrm{V}_{\mathrm{an}}, \mathrm{V}_{\mathrm{bn}}, \mathrm{V}_{\mathrm{cn}}$ where $\mathrm{n}$ refer to negative dc bus voltage is computed from $V_{\text {idc }}$ and the switch position.

A. Three - phase Inverters

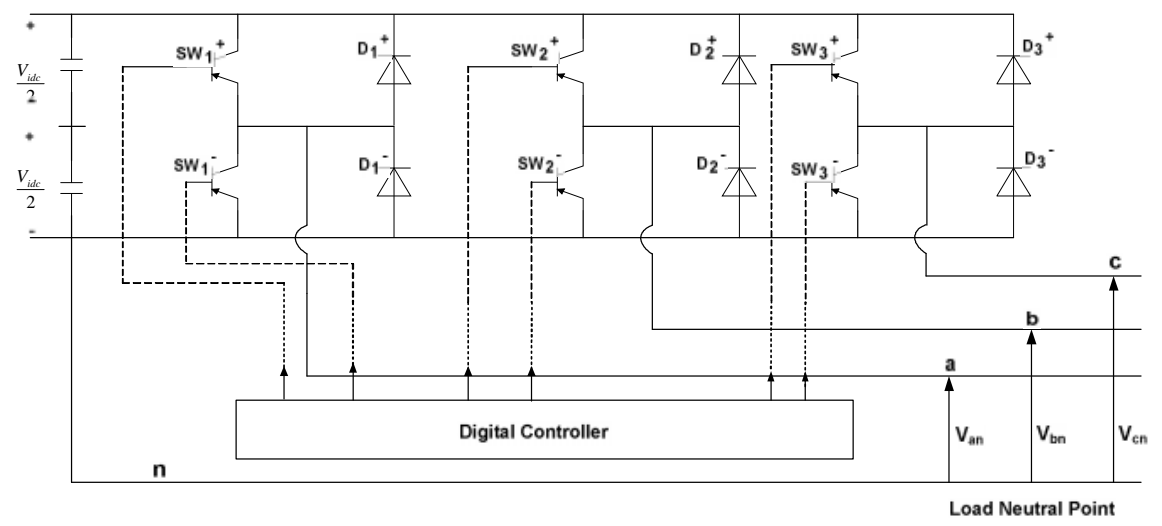

Figure (14)Operation of three - phase Inverter

For each leg, one of the two switches are on while, the other switch is off. The function of the pulse - width - modulation (PWM) is to determine the fundamental frequency of the output voltage.

If the input dc voltage $\mathrm{V}_{\text {idc }}$ is constant, then the magnitude of the fundamental frequency output AC voltage will be also constant. However, by changing the switching time $\mathrm{t}_{\mathrm{s}}=$ $1 / f_{s}$; where $f_{s}$ is the frequency of PWM. The frequency at which two switches of each leg are closed and opened, (On and Off), the fundamental frequency of the output 
voltage is determined. Therefore, a three - phase inverter has three terminals; that is, input terminal is supplied from a dc source, the output terminal provides three phase AC voltage and the third terminal is supplied with a control signal to the base of the power switch. The control signal is computed based on the desired frequency and magnitude of AC output voltage. The controller is a digital controller usually, a DSP (Digital Signal Processor) or u controller (micro - controller) [12].

B. Basic Operation of PWM Inverter As was pointed out, a three - phase inverter has three legs, one for each phase. Let us consider one leg and discuss PWM operation of a single - phase inverter.

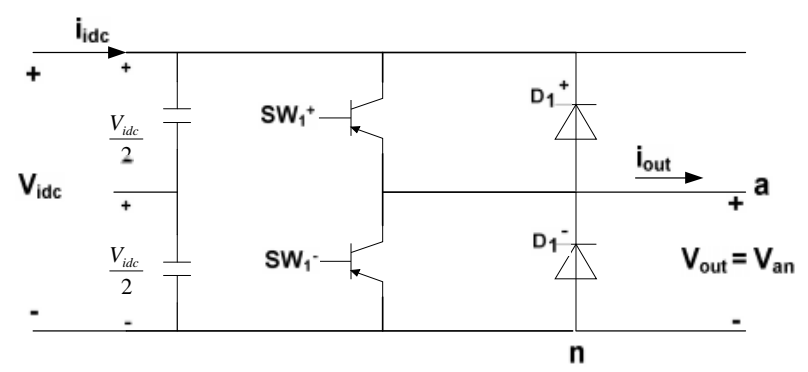

Figure (15) Operation of Single - phase PWM Inverter

The output voltage, $V_{\text {out }}=V_{a n}$ is filtered out of the unwanted harmonics and $V_{a n}$ is a sinusoidal voltage. Let us assume the inverter supplies an inductive load. Therefore for an inductive load, the current $i_{\text {out }}$ will lag the voltage $V_{\text {out }}$.

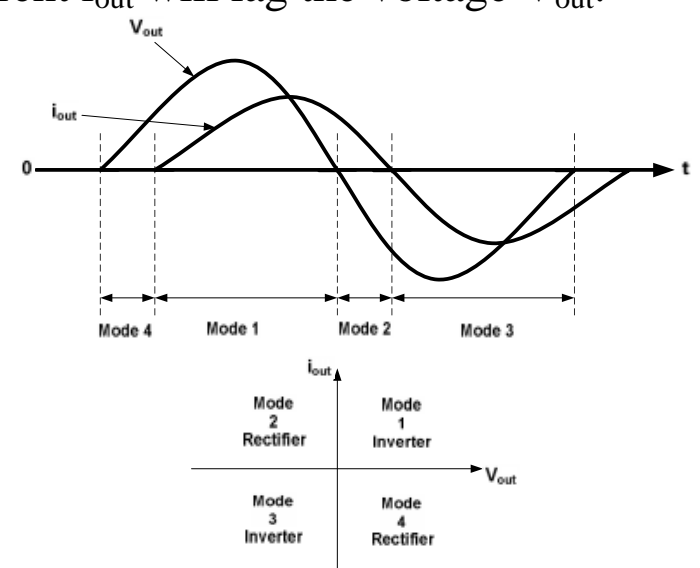

Figure (16) Four Modes of Inverter Operation

During mode 1 operation, both $\mathrm{V}_{\text {out }}$ and $\mathrm{i}_{\text {out }}$ are positive. Therefore, the converter operates as an inverter and $\mathrm{P}_{\text {out }}$ flows from DC side to AC side. During mode $2, \mathrm{i}_{\text {out }}$ is positive and is negative. In this mode, the converter operates as a rectifier, since the $\mathrm{P}_{\text {out }}$ flows from AC side to DC side. During mode3, $\mathrm{i}_{\text {out }}$ and $\mathrm{V}_{\text {out }}$ are both negative. Again converter operates as an inverter, since the $\mathrm{P}_{\text {out }}$ flows from $\mathrm{DC}$ side to $\mathrm{AC}$ side. 
During mode $4, \mathrm{~V}_{\text {out }}$ is positive and $\mathrm{i}_{\text {out }}$ is negative and this mode of operation can be designated as rectifier operation. Since $\mathrm{P}_{\text {out }}$ flows from the AC side to the DC side of the converter. Therefore, the single - phase converter of figure 13 can be operated as all four quadrants [12].

The sequence of switching policy for $\mathrm{SW}_{1}{ }^{+}$and $\mathrm{SW}_{1}{ }^{-}$can be generated by comparing the $V_{C}$ with a triangular wave form $V_{T}$ as shown below.

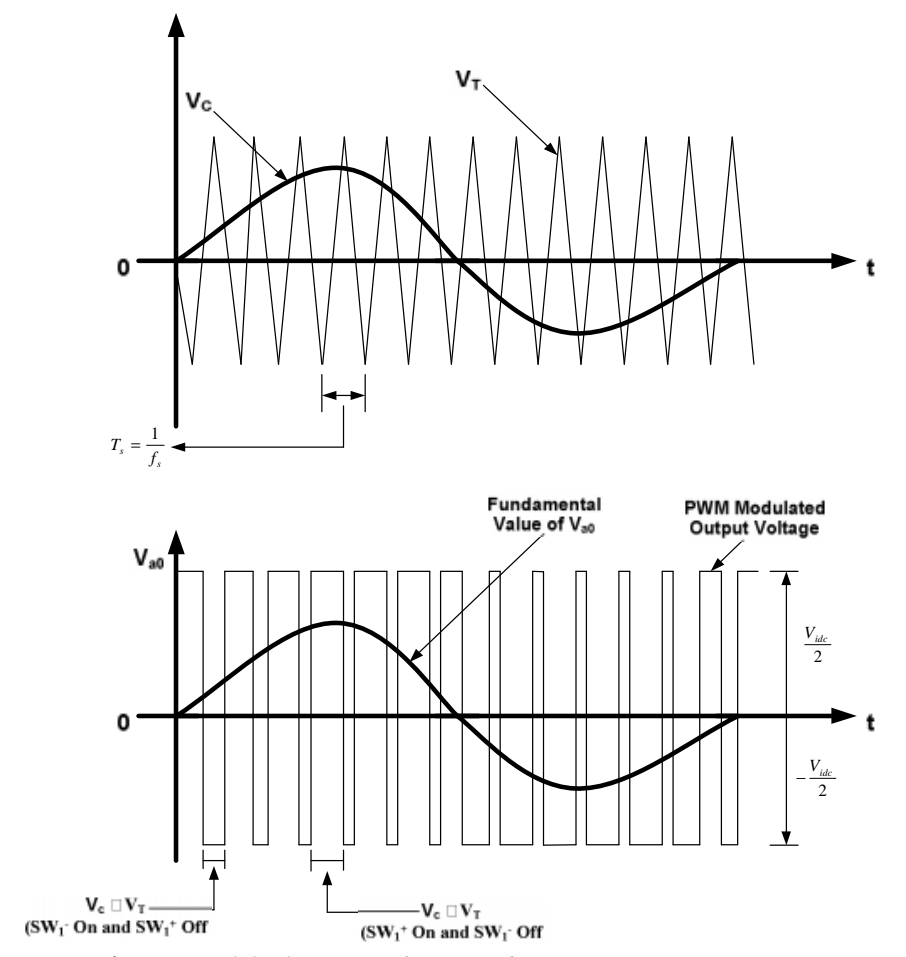

Figure (17) Single - phase PWM Operation

The sampling period $T_{S}=1 / f_{s}$ where $f_{S}$ is the frequency of the triangular waveform $V_{T}$ determines the switching sequence of $\mathrm{i}_{\text {out }}, \mathrm{V}_{\text {out }}$ plane during each cycle of the ac output. Let us assume that we would like to transfer power from DC side to AC side at frequency of $\omega_{\mathrm{e}}=2 \pi \mathrm{f}_{\mathrm{e}}$ and amplitude of $\mathrm{V}_{\max }$. Therefore control signal will have $\mathrm{V}_{\mathrm{C}}=$ $\mathrm{V}_{\max } \sin \omega_{\mathrm{e}} \mathrm{t}$ as our reference control signal input. We need to sample our control signal, $\mathrm{V}_{\mathrm{C}}$. We will discuss the required sampling rate later. During the sampling time, we turn on and turn off $\mathrm{SW}_{1}{ }^{+}$and $\mathrm{SW}_{1}{ }^{-}$such that our sampled $\mathrm{V}_{\text {idc }}$ has an output ac voltage with a fundamental frequency of $\mathrm{f}_{\mathrm{e}}$ of the control signal $\mathrm{V}_{\mathrm{C}}$.

Let us assume the control signal, $\mathrm{V}_{\mathrm{C}}$, has frequency of $\mathrm{f}_{\mathrm{e}}$, and amplitude of $\mathrm{V}_{\max }$.

$$
\mathrm{v}_{\mathrm{C}}=\mathrm{V}_{\mathrm{C}(\max )} \sin \omega_{\mathrm{e}} \mathrm{t} \quad, \omega_{\mathrm{e}}=2 \pi \mathrm{f}_{\mathrm{e}}
$$

Also, let us assume the triangular wave $\mathrm{V}_{\mathrm{T}}$ has a frequency of $f_{s}$ and sampling time of $T_{s}=\frac{1}{f_{s}}$ and amplitude of $\frac{V_{i d c}}{2}$ as shown before.

We will use the control signal to modulate the switch duty ratio to generate the PWM 
modulated wave. .

The amplitude of modulation is defined as $\quad M_{a}=\frac{V_{C(\max )}}{V_{T(\max )}}$

The frequency of modulation $\mathrm{M}_{\mathrm{f}}$ is defined as $\quad M_{f}=\frac{f_{s}}{f e}$

In the DC/AC converter, the power switches $\mathrm{SW}_{1}^{+}$and $\mathrm{SW}_{1}^{-}$are controlled by comparing $\mathrm{V}_{\mathrm{C}}$ and $\mathrm{V}_{\mathrm{T}}$ using the following constraints.

$$
\begin{aligned}
& \mathrm{V}_{\mathrm{c}} \mathrm{V}_{\mathrm{T}} \quad \mathrm{SW}_{1}{ }^{+} \text {is On } \\
& \mathrm{V}_{\mathrm{a} 0}=\frac{1}{2} \frac{V_{i d c}}{2} \\
& \mathrm{~V}_{\mathrm{c}} \quad \mathrm{V}_{\mathrm{T}} \quad \mathrm{SW}_{1}{ }_{1}^{-} \text {is On } \\
& \mathrm{V}_{\mathrm{a} 0}=-\frac{1}{2} \frac{V_{i d c}}{2}
\end{aligned}
$$

The output modulate voltage will be change between two values of $\frac{V_{i d c}}{2}$ and $-\frac{V_{i d c}}{2}$.

The output modulated voltage is a function of $M_{a}$ and $M_{f}$. Depending on the value $M_{a}$ and $\mathrm{M}_{\mathrm{f}}$, the harmonic components of the modulated voltage will be different.

C. Square - wave operation of DC/AC inverter.

In the square - wave switching policy of figure 17, each switch, that is, $\mathrm{SW}_{1}{ }^{+}$and $\mathrm{SW}_{1}^{-}$ is On for one half - cycle of the desired output frequency. This switching policy results in an output voltage wave form depicted by figure 18 .

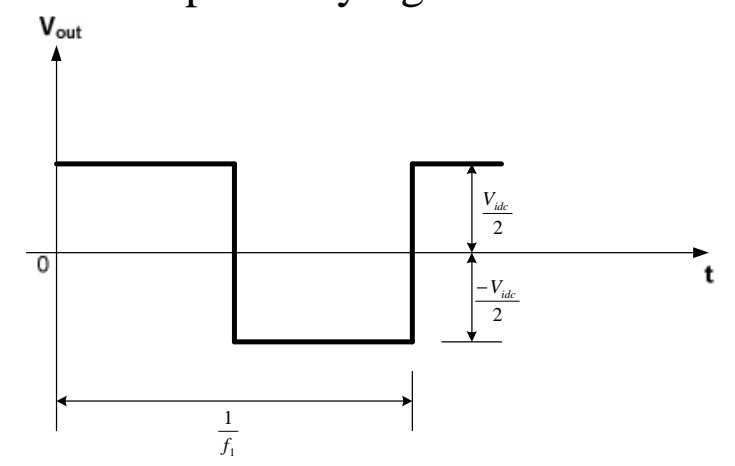

Figure (18) DC/AC Inverter operation with 180 degree switching policy

D. Single - phase and Full - Bridge Converters

In previous section, we have presented the PWM concepts analysis, the operation of single - phase inverter. Here, we will present half - bridge inverter and full - bridge inverters. In the following section, we will use the discussion here to present the operation of three - phase inverter. 


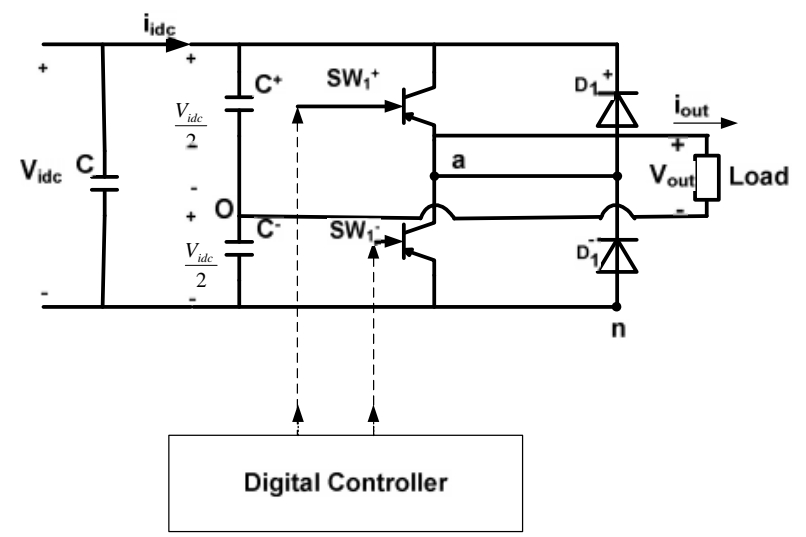

Figure (19) Single - phase half-Bridge Converter

Figure 19 depicts the half - bridge converter. To assure that the voltage at the midpoint of the two capacitors designated by point "O", remain constant with respect to the negative of dc bus. We will need to use to large capacitors $\mathrm{C}^{+}$and $\mathrm{C}^{-}$. This configuration is the same as one - leg converter that was presented earlier, and its wave forms [12].

When $\mathrm{SW}_{1}{ }^{+}$is On and $\mathrm{D}_{1}{ }^{+}$is Off, the modulate output voltage appears across the load. Similarly, when $\mathrm{SW}_{1}{ }^{-}$is $\mathrm{On}$ and $\mathrm{D}_{1}{ }^{+}$is Off, the modulated output voltage appears across the load. In either case, the output current divides equally between two capacitors. In a half - bridge converter of figure 19, the peak voltage and current ratings of the switches will be: $\mathrm{V}_{\text {peak }}=\mathrm{V}_{\text {idc }} ; \mathrm{i}_{\text {peak }}=\mathrm{i}_{\text {out peak }}$

A single - phase full - bridge converter is shown in figure 20.

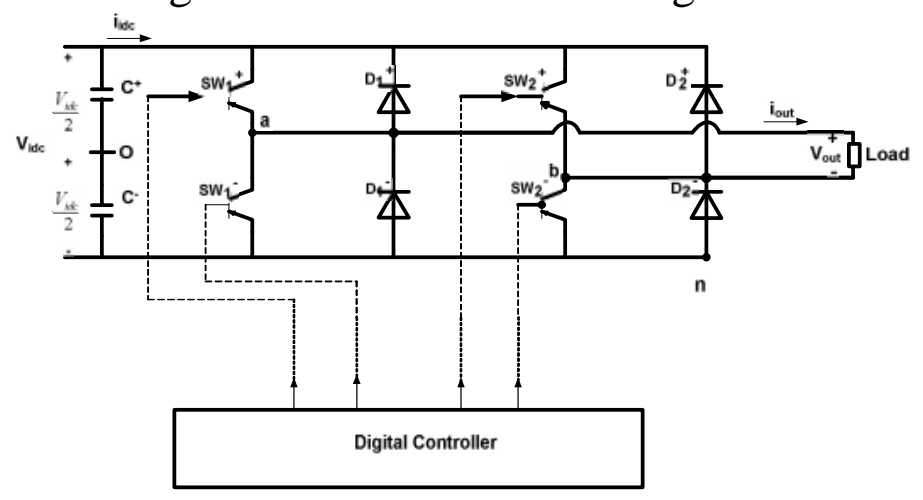

Figure (20) Single - phase Full-Bridge Converter.

This DC/AC converter has two legs. Each leg has two switches. The operation of each leg is as described before for the half - bridge single - phase converters [12]. For the converter of fig. 20, the $\mathrm{SW}_{1}{ }^{+}$and $\mathrm{SW}_{2}{ }^{+}$and $\mathrm{SW}_{1}{ }^{-}$and $\mathrm{SW}_{2}{ }^{+}$are switched as pairs. The switching policy is shown in fig. 21. 


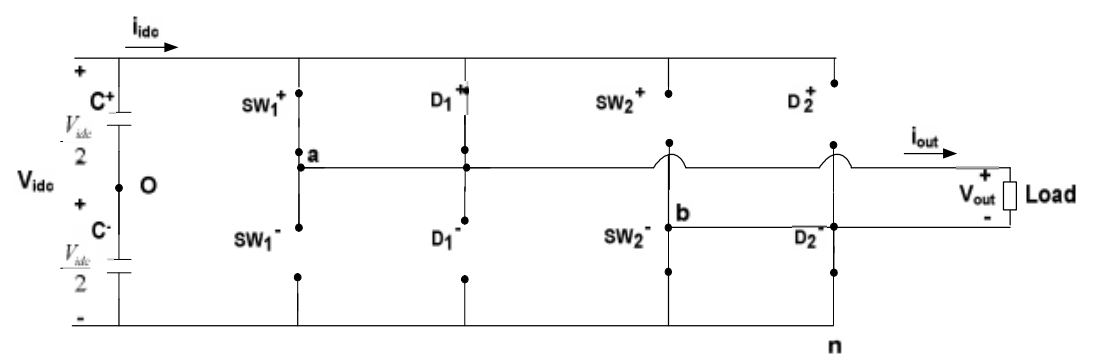

Figure (21) Single - phase Full - Bridge Converter Operation with two switches switched On as a pair.

$\mathrm{V}_{\text {out }}=\mathrm{V}_{\mathrm{a} \text { out }}(\mathrm{t})-\mathrm{V}_{\mathrm{b} \text { out }}(\mathrm{t})$

$$
=2 \mathrm{~V}_{\mathrm{ao}}(\mathrm{t})=\mathrm{V}_{\mathrm{idc}} \quad \text { peak to peak }
$$

Where

$\mathrm{V}_{\mathrm{C}}=\mathrm{V}_{\mathrm{C}(\max )} \sin \omega_{\mathrm{e}} \mathrm{t}$, $\omega_{\mathrm{e}}=2 \pi \mathrm{f}_{\mathrm{e}}$

$\mathrm{V}_{\mathrm{C}}=\sqrt{2} \mathrm{~V}_{\mathrm{C}(\max )}(\mathrm{RMS})$

And $f_{e}$ the fundamental frequency of the control signal, $V_{C}$.

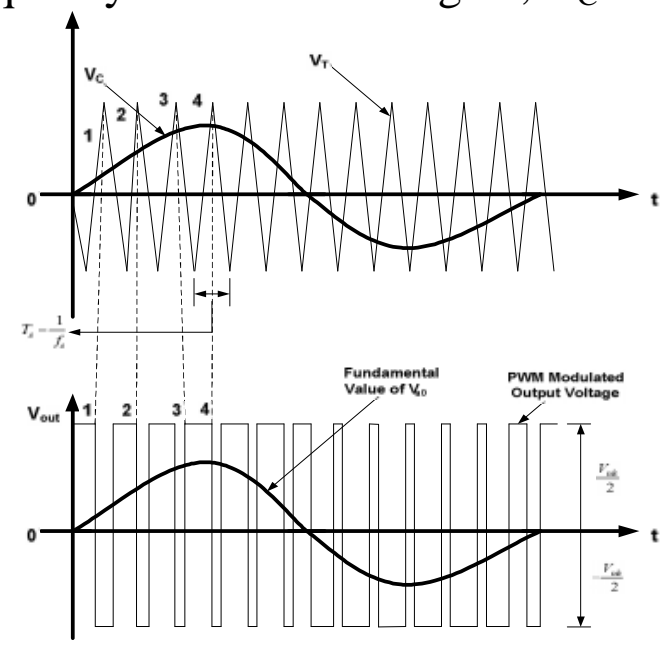

Figure (22) PWM bipolar - voltage switching operation

The same as one - leg converter, the peak of the fundamental frequency component of the modulated voltage can be expressed as

$\mathrm{V}_{\text {out (Fundamental) }}=\mathrm{M}_{\mathrm{a}} \mathrm{V}_{\text {idc }}$

Where the amplitude of the modulation is defined as

$M_{a}=\frac{V_{C(\operatorname{Max})}}{V_{T(\operatorname{Max})}}$

And $\mathrm{M}_{\mathrm{a}}$ is less than one, we will have

$\mathrm{V}_{\text {idc }} \quad \mathrm{V}_{\text {out (peak) }} \quad \frac{4}{\pi} \mathrm{V}_{\text {idc }}$

Where the frequency of modulation $\mathrm{M}_{\mathrm{f}}$ is defined as 
$M_{f}=\frac{f_{s}}{f_{e}}$ and $f_{s}=\frac{1}{T_{s}}$

Where $T_{s}$ is the sampling time (the period of the triangular waveform).

E. Three - phase Converters

From our previous presentation, we can construct a three - phase converter as depicted below:

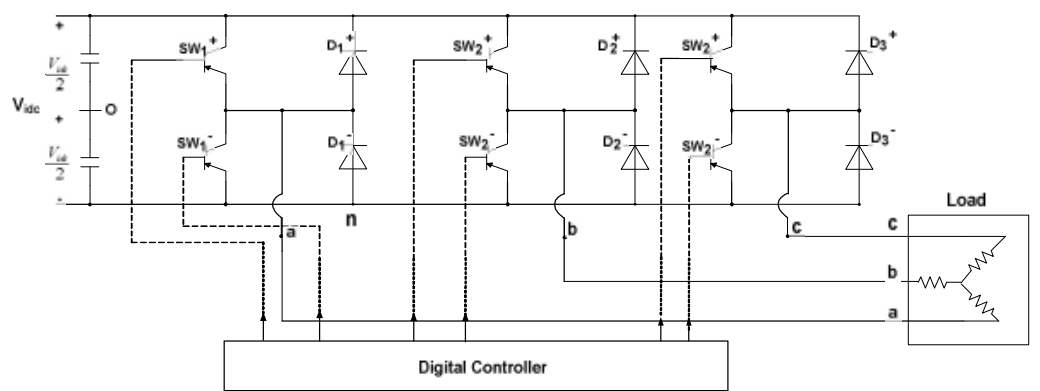

Figure (23) Operation of three - phase Converter.

As shown in figure 23, we have three single phase converters that are connected to a common dc bus to make a three - phase converter. The modulated output voltage of each leg has the same waveform of a single - phase converter [12].

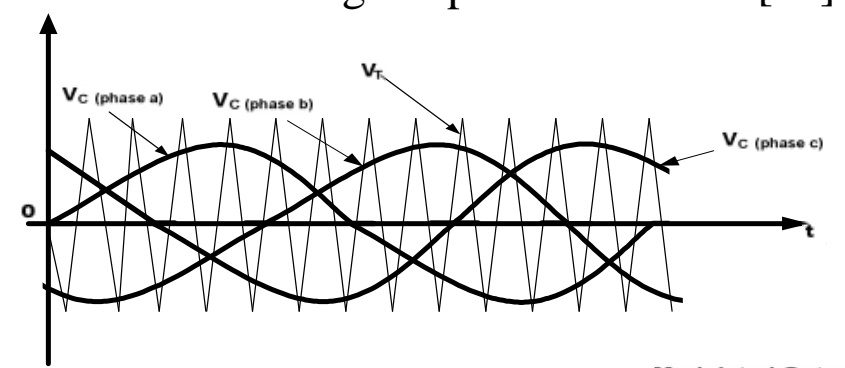

Modulated Output

Voltage of phase a

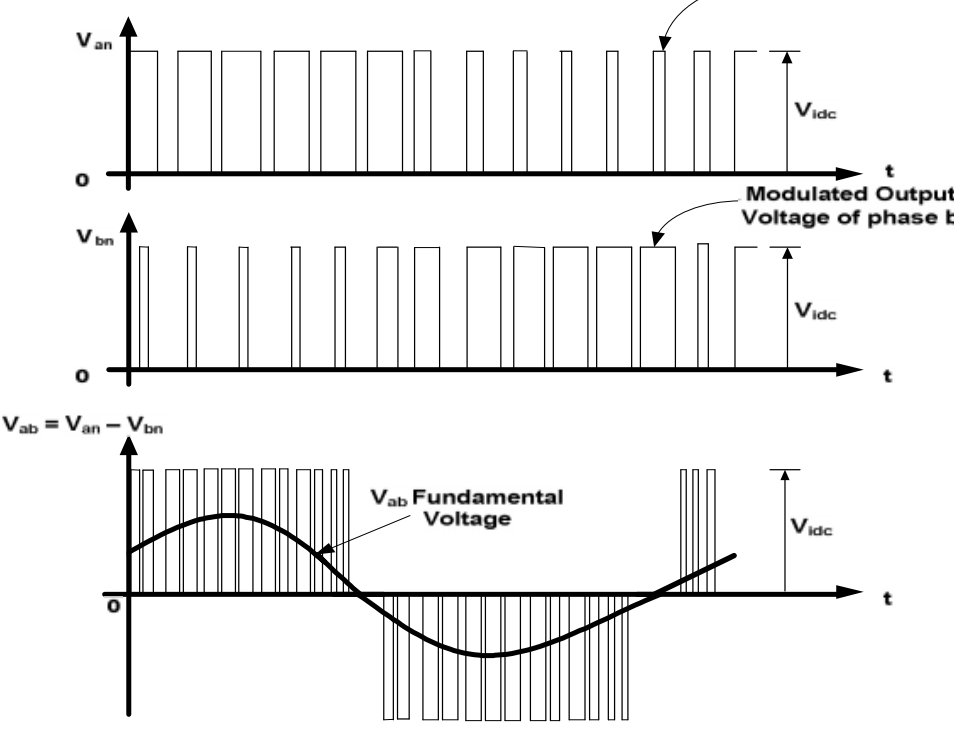

Figure (24) PWM Operation of a Three - phase Converter. 
As it was discussed in the operation of a single - phase converter, one switch is On in each leg of the three - phase converter. Therefore, in each phase, for example in phase $\mathrm{a}, \mathrm{V}_{\mathrm{an}}$ with respect to the negative dc bus depends on $\mathrm{V}_{\mathrm{idc}}$ and the switch status $\mathrm{SW}_{1}{ }^{+}$and $\mathrm{SW}_{1}^{-}$. This can be seen from figure 24 .

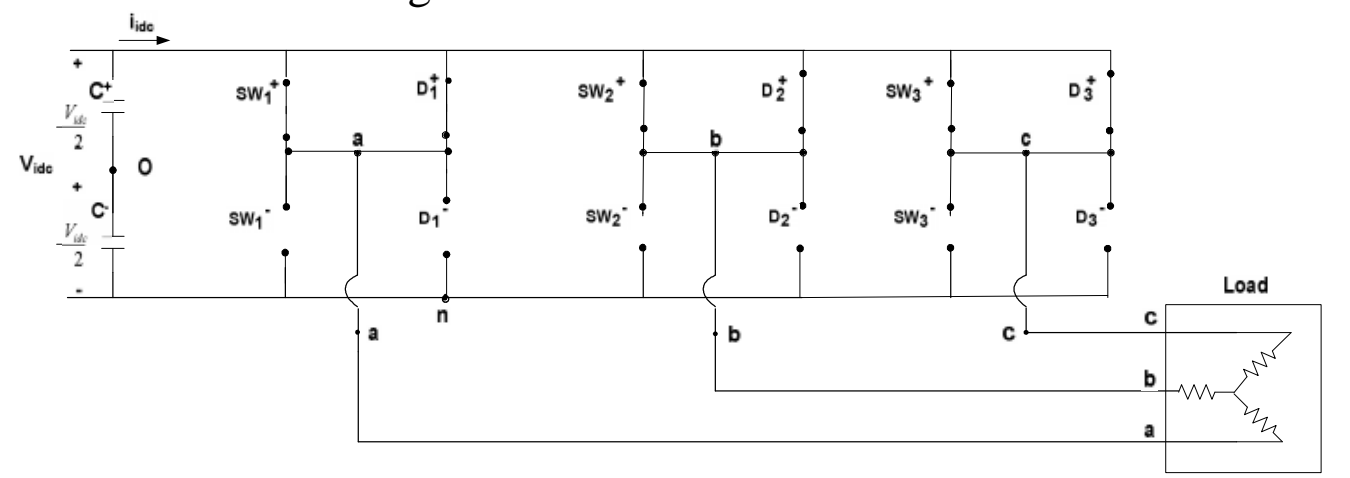

Figure (25)Operation of a three - phase Converter when $\mathrm{SW}_{1}^{+}, \mathrm{SW}_{2}{ }^{+}$and $\mathrm{SW}_{3}{ }^{+}$are On.

If we closely study the modulated output voltage of each phase (phase a and phase $b$ are shown in figure 23), we will conclude that the output voltage is independent of the output load current since one of the switches of each leg is always on. (See figure 25) The control objective is the same as discussed for a single - phase converter, that is the pulse - width modulation seeks to control the modulated output voltage of each phase such that the magnitude and frequency of the fundamental output voltage is the same as the control voltage as the power switches samples the dc bus voltage.

To obtain a balanced three - phase modulated output voltage, the same triangular voltage waveform is compared with the three - phase balanced control voltage as shown. The shape of the modulated voltage is function of both the amplitude and frequency modulation [12]. Recall, that

$$
M_{f}=\frac{f_{s}}{f_{e}} \quad \text { and } \quad f_{s}=\frac{1}{T_{s}}
$$

Where $T_{s}$ is the sampling time, that is, the period of the triangular waveform, and $f_{e}$ the frequency of the control voltage.

$$
M_{a}=\frac{V_{C(\max )}}{V_{T(\max )}}
$$

The peak fundamental - frequency component of the modulated voltage, when $\mathrm{M}_{\mathrm{a}}$ is less than one, is given

$\mathrm{V}_{\text {an(peak) }}=M_{a} \frac{V_{i d c}}{2}$

We can calculate the line - to - line voltage as

$$
\mathrm{V}_{\text {line - line }}=\mathrm{V}_{\mathrm{LL}}=\sqrt{3} \mathrm{~V}_{\mathrm{an}}(\mathrm{RMS})
$$


Therefore, when $\mathrm{M}_{\mathrm{a}} \leq 1$.

$$
\mathrm{V}_{\mathrm{LL}}=\sqrt{3} \frac{V_{\text {peak }}}{\sqrt{2}}=\frac{\sqrt{3}}{2 \sqrt{2}} \mathrm{M}_{\mathrm{a}} \mathrm{V}_{\mathrm{idc}}
$$

When $M_{a}$ is less than one, the output voltage is directly proportional to the $M_{a}$. Therefore, this is referred to as linear region of the converter operation.

When $\mathrm{M}_{\mathrm{a}}$ is greater than one, the converter is operating in over modulation region. For this mode operation, the peak value of the $\mathrm{V}_{\mathrm{C}}$, control voltage is allowed to exceed the peak value of $\mathrm{V}_{\mathrm{T}}$, the triangular waveform. In this region, the fundamental - frequency of the modulated voltage does not increase linearly with $\mathrm{M}_{\mathrm{a}}$. When $\mathrm{M}_{\mathrm{a}}$ is very high, the converter operates as a square wave converter.

\section{MATLAB Inverters Reviews Results}
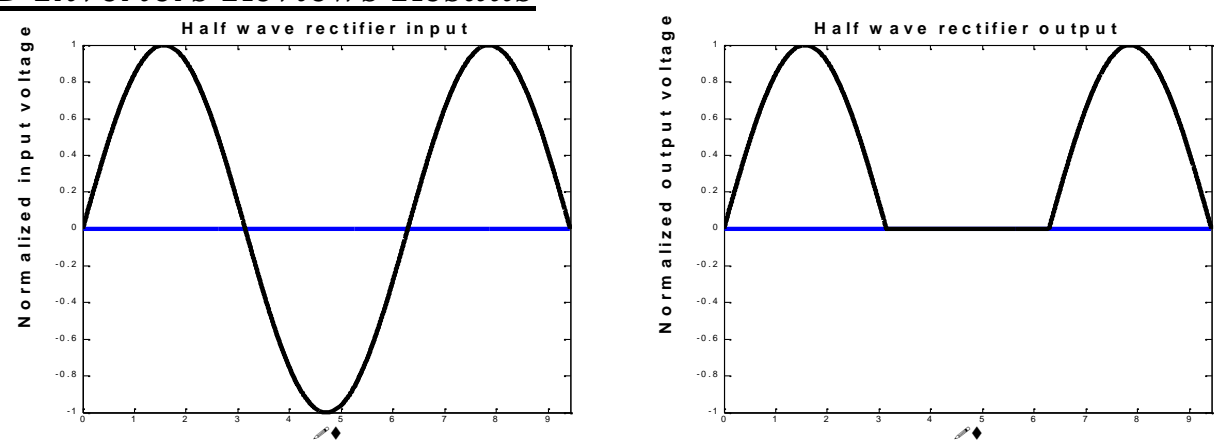

Figure (26)Half Wave uncontrolled rectifier plots

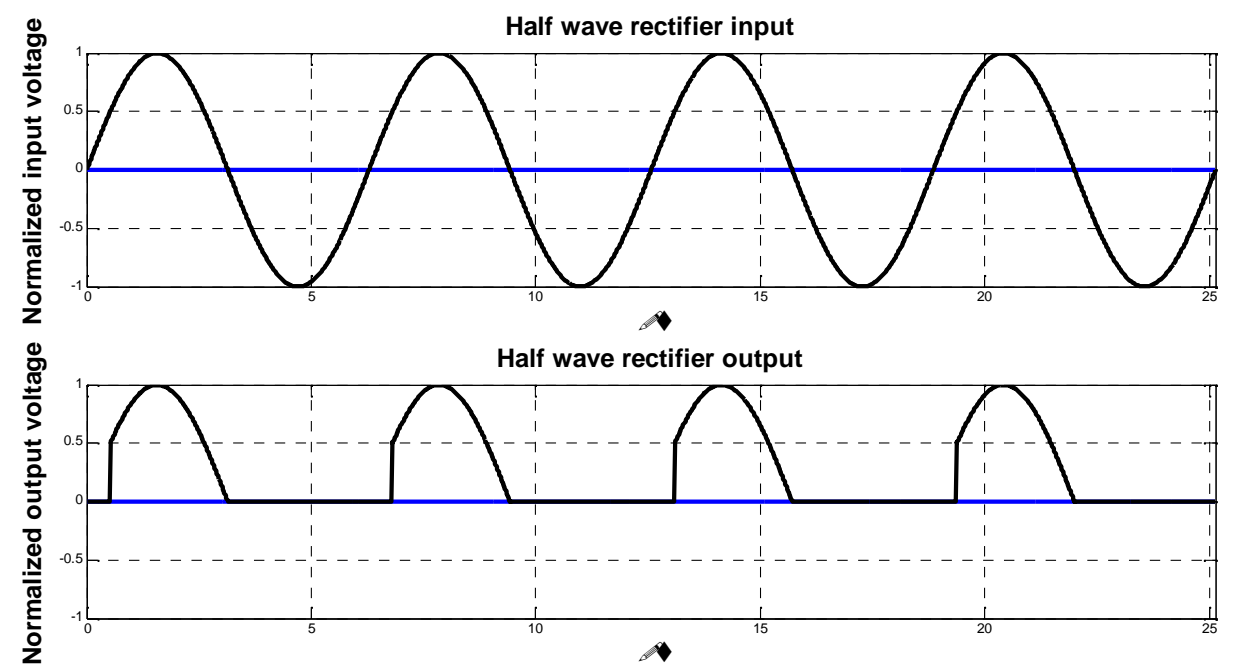

Figure (27)Half Wave controlled rectifier plots 


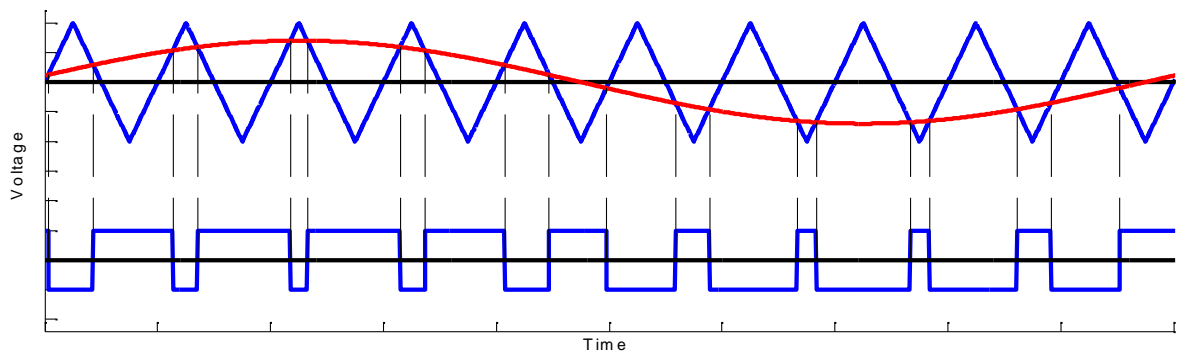

Figure (28) Single - phase PWM Operation
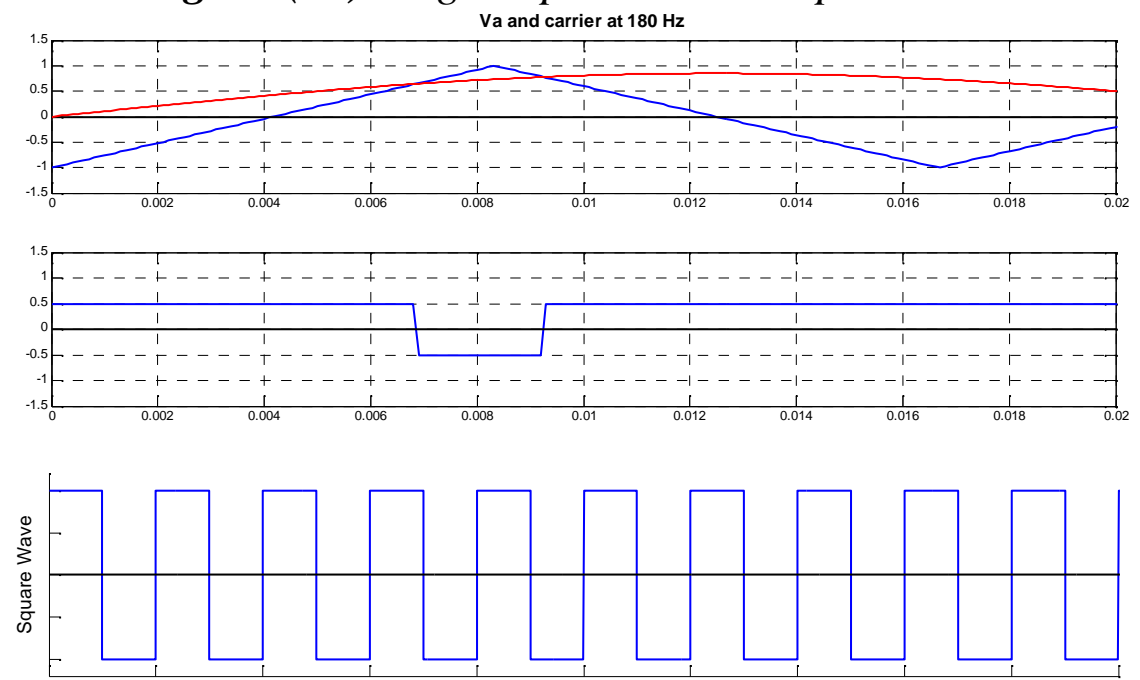

Figure (29) DC/AC Inverter operation with 180 degree switching policy

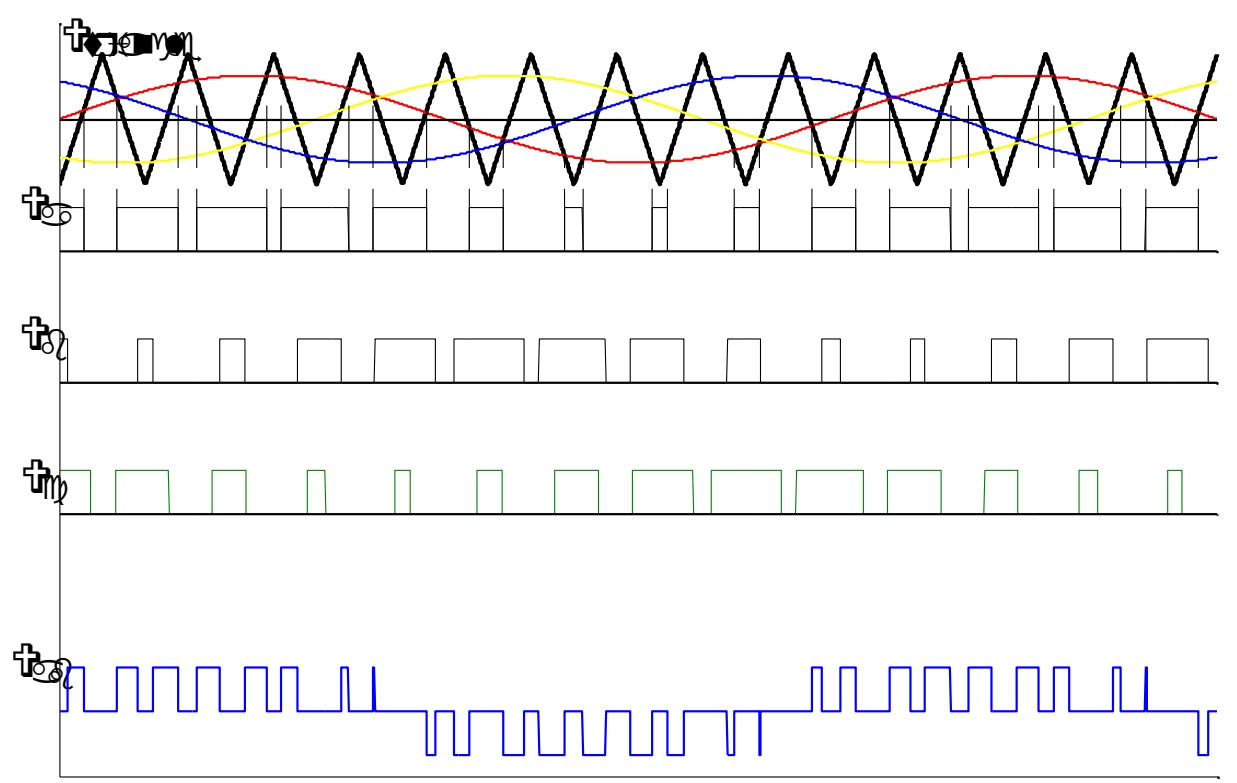

Figure (30) PWM Operation of a Three - phase Converter. 


\section{Maximum Power Point for Resistive Load}

When a PV module is directly coupled to a load, the PV module's operating point will be at the intersection of its $I-V$ curve and the load line which is the $I-V$ relationship of load. For example in figure 32 , a resistive load has a straight line with a slope of $1 / R_{\text {Load }}$ as shown in Figure 33. In other words, the impedance of load dictates the operating condition of the PV module. In general, this operating point is seldom at the PV module's MPP, thus it is not producing the maximum power. A PV array is usually oversized to compensate for a low power yield during winter months. This mismatching between a PV module and a load requires further over-sizing of the PV array and thus increases the overall system cost. To mitigate this problem, a maximum power point tracker (MPPT) can be used to maintain the PV module's operating point at the MPP. MPPTs can extract more than $97 \%$ of the PV power when properly optimized. This section discusses the $I-V$ characteristics of $\mathrm{PV}$ module and resistive load, matching between the two, and the use of DC-DC converters as a means of MPPT.

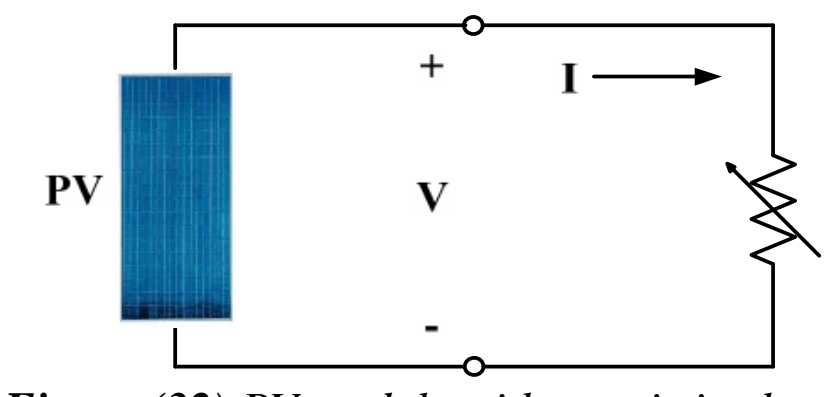

Figure (32) PV module with a resistive load

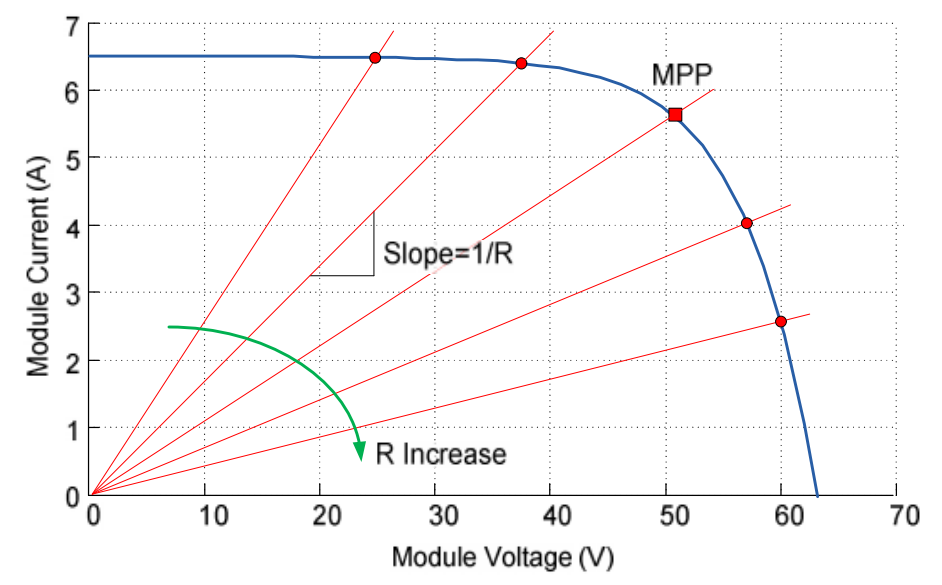

Figure (33) I-V curves of $P V$ module and various resistive loads $\left(1 \mathrm{~kW} / \mathrm{m}^{2}, 25^{\circ} \mathrm{C}\right)$

\section{$\underline{\text { 8. DC-DC Converter }}$}


The heart of MPPT hardware is a switch-mode DC-DC converter. It is widely used in DC power supplies and DC motor drives for the purpose of converting unregulated DC input into a controlled DC output at a desired voltage level [40]. MPPT uses the same converter for a different purpose: regulating the input voltage at the PV MPP and providing load-matching for the maximum power transfer.

\section{A. Topologies}

There are a number of different topologies for DC-DC converters. They are categorized into isolated or non-isolated topologies. The isolated topologies use a small-sized highfrequency electrical isolation transformer which provides the benefits of DC isolation between input and output, and step up or down of output voltage by changing the transformer turns ratio. They are very often used in switch-mode DC power supplies [41]. Popular topologies for a majority of the applications are fly-back, half-bridge, and full-bridge. In PV applications, the grid-tied systems often use these types of topologies when electrical isolation is preferred for safety reasons. Non-isolated topologies do not have isolation transformers. These topologies are further categorized into three types: step down (buck), step up (boost), and step up \& down (buck-boost). The buck topology is used for voltage step-down. In PV applications, the buck type converter is usually used for charging batteries and in LCB for water pumping systems. The boost topology is used for stepping up the voltage. The grid-tied systems use a boost type converter to step up the output voltage to the utility level before the inverter stage. Then, there are topologies able to step up and down the voltage such as: buck-boost, Cúk, and SEPIC (stands for Single Ended Primary Inductor Converter). For PV system with batteries, the MPP of commercial PV module is set above the charging voltage of batteries for most combinations of irradiance and temperature. A buck converter can operate at the MPP under most conditions, but it cannot do so when the MPP goes below the battery charging voltage under a low-irradiance and high-temperature condition. Thus, the additional boost capability can slightly increase the overall efficiency [42].

\section{B. Cúk and SEPIC Converters}

The buck converter is the simplest topology and easiest to understand and design, however it exhibits the most severe destructive failure mode of all configurations [41]. Another disadvantage is that the input current is discontinuous because of the switch located at the input, thus good input filter design is essential. Other topologies capable of voltage step-down are Cúk and SEPIC. Even though their voltage step-up function is optional for LCB application, they have several advantages over the buck converter. They provide capacitive isolation which protects against switch failure (unlike the buck topology). The input current of the Cúk and SEPIC topologies is continuous, and they can draw a ripple free current from a PV array that is important for efficient MPPT. Figure 34 shows a circuit diagram of the basic Cúk converter. It is named after its inventor. It can provide the output voltage that is higher or lower than the input voltage. 
The SEPIC, a derivative of the Cúk converter, is also able to step up and down the voltage. Figure 35 shows a circuit diagram of the basic SEPIC converter. The characteristics of two topologies are very similar. They both use a capacitor as the main energy storage. As a result, the input current is continuous. The circuits have low switching losses and high efficiency [41]. The main difference is that the Cúk converter has a polarity of the output voltage reverse to the input voltage. The input and output of SEPIC converter have the same voltage polarity; therefore the SEPIC topology is sometimes preferred to the Cúk topology. SEPIC may be also preferred for battery charging systems because the diode placed on the output stage works as a blocking diode preventing an adverse current going to PV source from the battery. The same diode, however, gives the disadvantage of high-ripple output current. On the other hand, the Cúk converter can provide a better output current characteristic due to the inductor on the output stage [40]. Therefore, this paper decides on the Cúk converter because of the good input and output current characteristics.

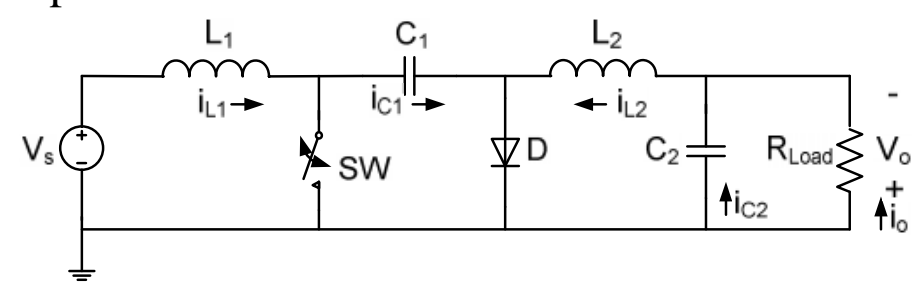

Figure (34) Circuit diagram of basic Cúk converter

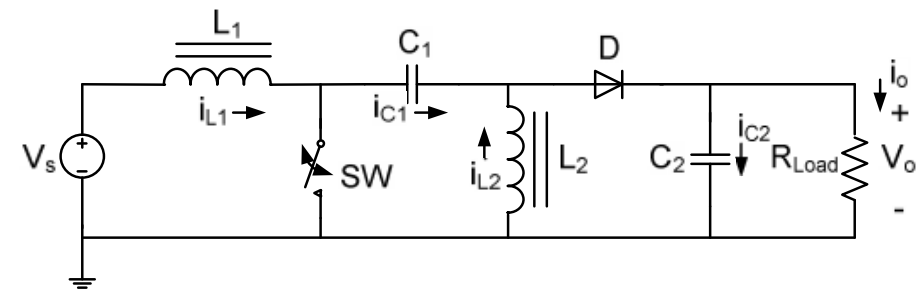

Figure (35) Circuit diagram of basic SEPIC converter

\section{Basic Operation of Cúk Converter}

The basic operation of Cúk converter in continuous conduction mode is explained here. In steady state, the average inductor voltages are zero, thus by applying Kirchoff's voltage law $(\mathrm{KVL})$ around outermost loop of the circuit shown in figure 34 .

$$
\mathrm{V}_{\mathrm{Cl}}=\mathrm{V}_{\mathrm{s}}+\mathrm{V}_{\mathrm{o}}
$$

Assume the capacitor $\left(\mathrm{C}_{1}\right)$ is large enough and its voltage is ripple free even though it stores and transfer large amount of energy from input to output [40] (this requires a good low ESR capacitor). The initial condition is when the input voltage is turned on and switch (SW) is off. The diode (D) is forward biased, and the capacitor $\left(\mathrm{C}_{1}\right)$ is being charged. The operation of circuit can be divided into two modes.

Mode 1: When SW turns ON, the circuit becomes one shown in figure 36. 


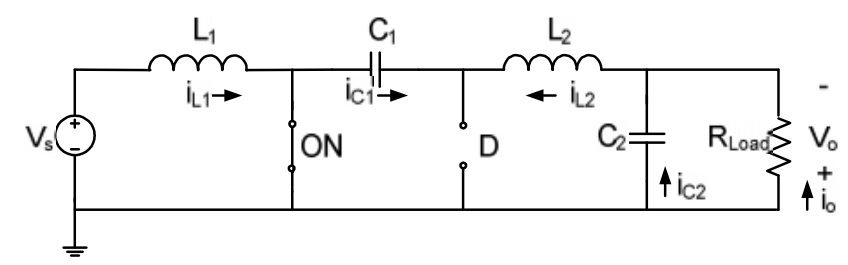

Figure (36) Basic Cúk converter when the switch is $O N$

The voltage of the capacitor $\left(\mathrm{C}_{1}\right)$ makes the diode (D) reverse-biased and turned off. The capacitor $\left(\mathrm{C}_{1}\right)$ discharge its energy to the load through the loop formed with $\mathrm{SW}$, $\mathrm{C}_{2}, \mathrm{R}_{\mathrm{Load}}$, and $\mathrm{L}_{2}$. The inductors are large enough, so assume that their currents are ripple free. Thus, the following relationship is established.

$$
-\mathrm{I}_{\mathrm{C} 1}=\mathrm{I}_{\mathrm{L} 2}
$$

Mode 2: When SW turns OFF, the circuit becomes one shown in figure 37.

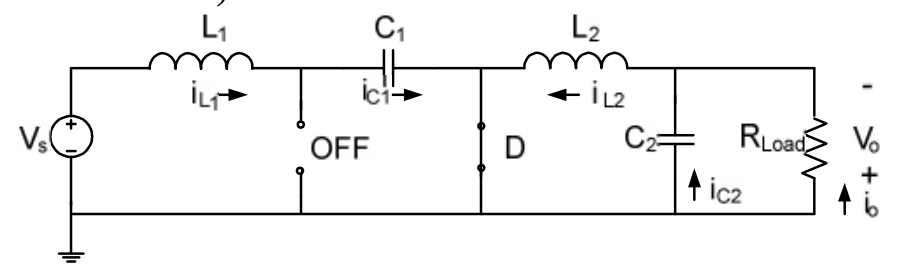

Figure (37) Basic Cúk converter when the switch is OFF

The capacitor $\left(\mathrm{C}_{1}\right)$ is getting charged by the input $\left(\mathrm{V}_{\mathrm{s}}\right)$ through the inductor $\left(\mathrm{L}_{1}\right)$. The energy stored in the inductor $\left(\mathrm{L}_{2}\right)$ is transfer to the load through the loop formed by $\mathrm{D}$, $\mathrm{C}_{2}$, and $\mathrm{R}_{\mathrm{Load}}$. Thus, the following relationship is established.

$$
\mathrm{I}_{\mathrm{C} 1}=\mathrm{I}_{\mathrm{L} 1}
$$

For periodic operation, the average capacitor current is zero. Thus, from the equation (33) and (34):

$$
\begin{gathered}
{\left[\left.\mathrm{I}_{\mathrm{C} 1}\right|_{\text {SwON }} . \mathrm{DT}+\left[\mathrm{I}_{\mathrm{C} 1} \mid{ }_{\text {SWOFF }}\right] .(1-\mathrm{D}) \mathrm{T}=0\right.} \\
-\mathrm{I}_{\mathrm{L} 2} \cdot \mathrm{DT}+\mathrm{I}_{\mathrm{L} 1} \cdot(1-\mathrm{D}) \mathrm{T}=0 \\
\mathrm{I}_{\mathrm{L} 1} / \mathrm{I}_{\mathrm{L} 2}=\mathrm{D} /(1-\mathrm{D})
\end{gathered}
$$

where: $D$ is the duty cycle $(0<D<1)$, and $T$ is the switching period.

Assuming that this is an ideal converter, the average power supplied by the source must be the same as the average power absorbed by the load.

$$
\begin{gathered}
\mathrm{P}_{\mathrm{in}}=\mathrm{P}_{\text {out }} \\
\mathrm{V}_{\mathrm{s}} \cdot \mathrm{I}_{\mathrm{L} 1}=\mathrm{V}_{\mathrm{o}} \cdot \mathrm{I}_{\mathrm{L} 2} \\
\mathrm{I}_{\mathrm{L} 1} / \mathrm{I}_{\mathrm{L} 2}=\mathrm{V}_{\mathrm{o}} / \mathrm{V}_{\mathrm{s}}
\end{gathered}
$$

Combining the equation (37) and (40), the following voltage transfer function is derived [40].

$$
\mathrm{V}_{\mathrm{o}} / \mathrm{V}_{\mathrm{s}}=\mathrm{D} /(1-\mathrm{D})
$$

Its relationship to the duty cycle $(D)$ is:

If $0<D<0.5$ the output is smaller than the input. 
If $D=0.5$ the output is the same as the input.

If $0.5<D<1$ the output is larger than the input.

D. Mechanism of Load Matching

As described before, when PV is directly coupled with a load, the operating point of PV is dictated by the load (or impedance to be specific). The impedance of load is described as below.

$$
\mathrm{R}_{\text {Load }}=\mathrm{V}_{\mathrm{o}} / \mathrm{I}_{\mathrm{o}}
$$

Where: $\mathrm{V}_{\mathrm{o}}$ is the output voltage, and Io is the output current.

The optimal load for PV is described as:

$$
\mathrm{R}_{\mathrm{opt}}=\mathrm{V}_{\mathrm{MPP}} / \mathrm{I}_{\mathrm{MPP}}
$$

Where: $V_{\text {MPP }}$ and $I_{\text {MPP }}$ are the voltage and current at the MPP respectively. When the value of $R_{\text {Load }}$ matches with that of $R_{\text {opt }}$, the maximum power transfer from PV to the load will occur.

These two are, however, independent and rarely matches in practice. The goal of the MPPT is to match the impedance of load to the optimal impedance of PV.

The following is an example of load matching using an ideal (loss-less) Cúk converter. From the equation (41):

$$
V_{s}=\frac{1-D}{D} V_{o}
$$

From the equation (40)

$$
\frac{I_{s}}{I_{o}}=\frac{I_{L 1}}{I_{L 2}}=\frac{V_{o}}{V_{s}}
$$

From the equation (44) and (45)

$$
I_{s}=\frac{D}{1-D} I_{o}
$$

From the equation (44) and (46), the input impedance of the converter is:

$$
R_{i n}=\frac{V_{s}}{I_{s}}=\frac{(1-D)^{2}}{D^{2}} \cdot \frac{V_{o}}{I_{o}}=\frac{(1-D)^{2}}{D^{2}} \cdot R_{\text {Load }}
$$

As shown in figure 8 , the impedance seem by $\mathrm{PV}$ is the input impedance of the converter $\left(R_{i n}\right)$. By changing the duty cycle (D), the value of $R_{\text {in }}$ can be matched with that of $R_{\text {opt }}$. Therefore, the impedance of the load can be anything as long as the duty cycle is adjusted accordingly.

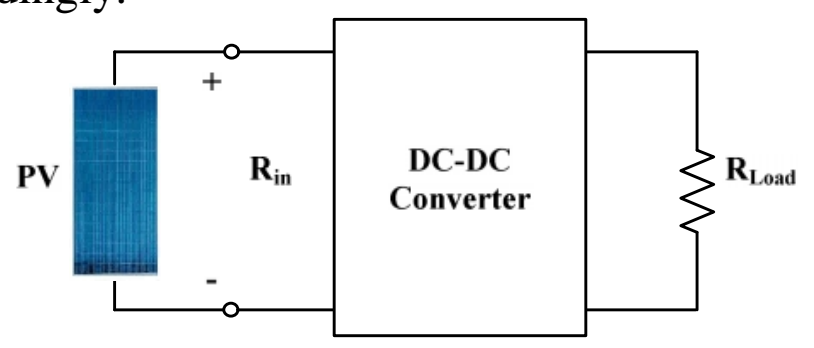

Figure (38) The impedance seen by $P V$ is $R_{\text {in }}$ that is adjustable by duty cycle (D) 


\section{E. Maximum Power Point Algorithm}

The location of the MPP in the $I-V$ plane is not known beforehand and always changes dynamically depending on irradiance and temperature. Therefore, the MPP needs to be located by tracking algorithm, which is the heart of MPPT controller. The example of resistive load matching is elaborated here to show how the output voltage and current change with varying irradiation and temperature. The maximum power transfer occurs when the input impedance of converter matches with the optimal impedance of PV module, as described in the equation below.

$$
R_{i n}=R_{\text {opt }}=\frac{V_{M P P}}{I_{M P P}}
$$

The required duty cycle (D) for the Cúk converter is:

The converter output voltage is:

$$
D=\frac{1}{1+\sqrt{\frac{R_{\text {in }}}{R_{\text {Load }}}}}
$$

$$
V_{o}=\frac{D}{1-D} V_{s}
$$

The converter output voltage is:

$$
I_{o}=\frac{1-D}{D} I_{s}
$$

It should be notified that, if the application requires a constant voltage, it must employ batteries to maintain the voltage constant. Also, of course, in reality DC-DC converter used in MPPT is not $100 \%$ efficient. The efficiency gain from MPPT is large, but the system needs to take efficiency loss by DC-DC converter into account. There is also tradeoff between efficiency and the cost. It is necessary for PV system engineers to perform economic analysis of different systems and also necessary to seek other methods of efficiency improvement such as the use of a sun tracker.

\section{Simulation Results}

The calculation results are presented by two ways: one in 2D figures, and other with the use of 3D figures. These results are based on PV module data and the MATLAB simulation model which implemented before. Relations between all possible predicted resistances values for all the entire I-V curves with the desired optimum resistance values are presented at the first from figure 39 to figure 42 . We want the converter to make the load matching at the points of intersections between the curves for the most probable global values of the load resistances and the straight lines of optimum load values in order to transfer the required maximum power for the resistive load. 


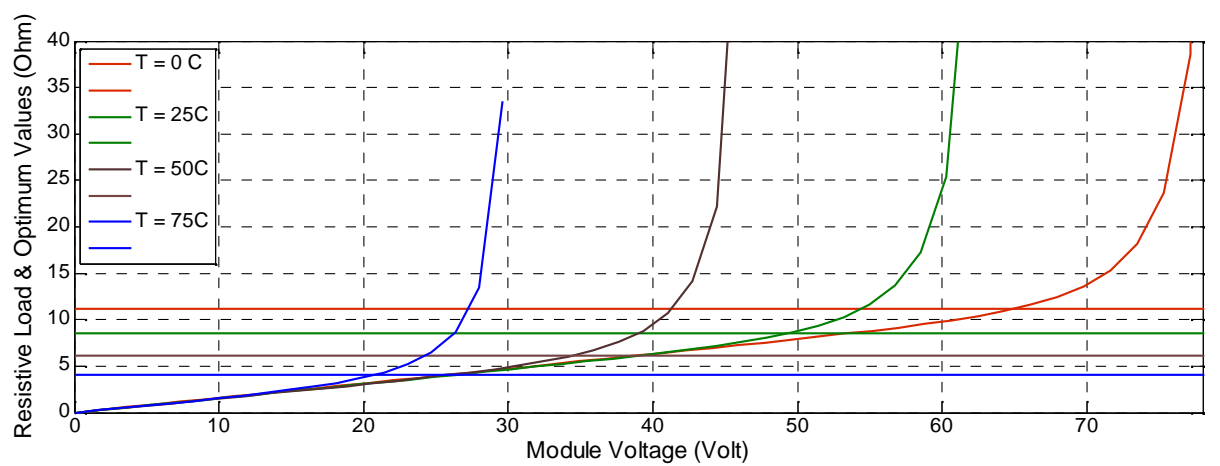

Figure (39) Resistive load and Optimum resistance values with Voltage at $1 \mathrm{~kW} / \mathrm{m}^{2}$ Irradiance

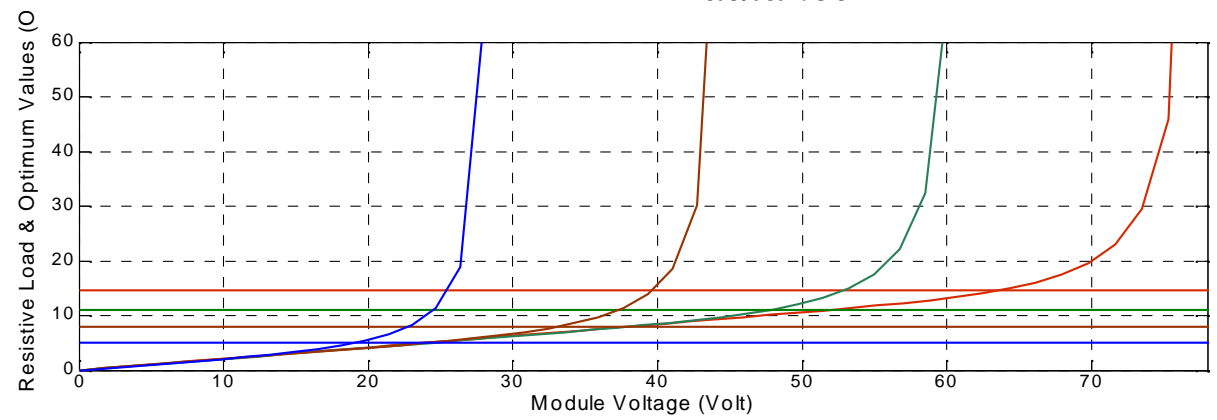

Figure (40) Resistive load and Optimum resistance values with Voltage at $0.75 \mathrm{~kW} / \mathrm{m}^{2}$ Irradiance

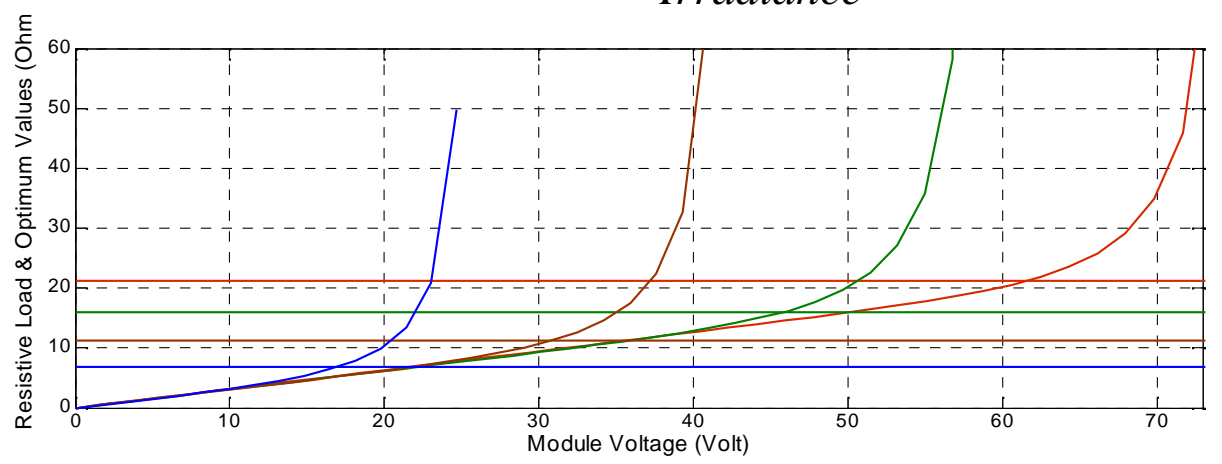

Figure (41) Resistive load and Optimum resistance values with Voltage at $0.50 \mathrm{~kW} / \mathrm{m}^{2}$ Irradiance

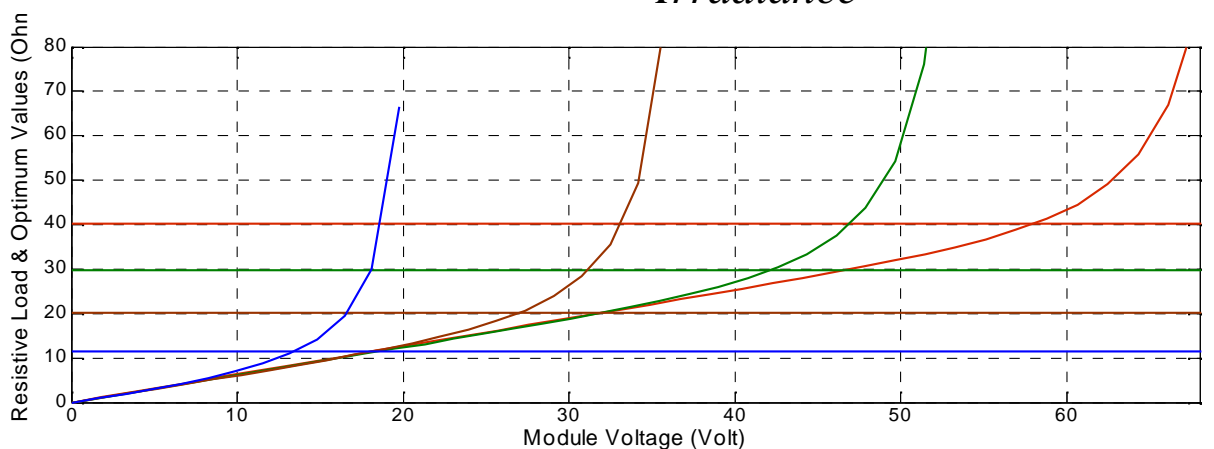

Figure (42) Resistive load and Optimum resistance values with Voltage at $0.25 \mathrm{~kW} / \mathrm{m}^{2}$ Irradiance 
After that, a set of $3 \mathrm{D}$ figures (from fig. 43 to fig. 50) are proposed to cover the most probable situations at various irradiance, various temperature with the current, and the voltage of the PV module. All these figures are based on the MATLAB modeling introduced before.

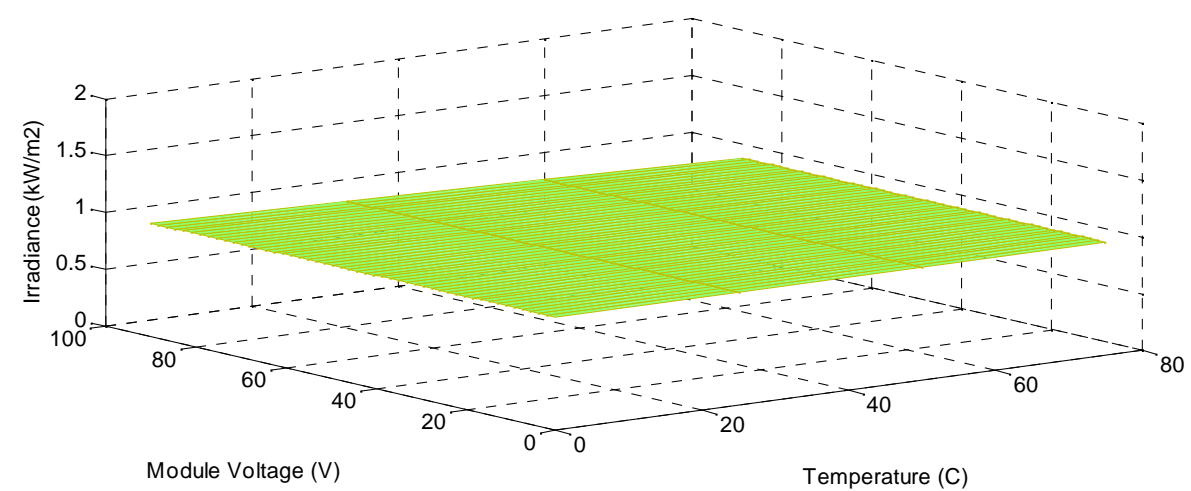

Figure (43) Voltage \& Temp.\& $\left(1 \mathrm{~kW} / \mathrm{m}^{2}\right)$ Irradiance

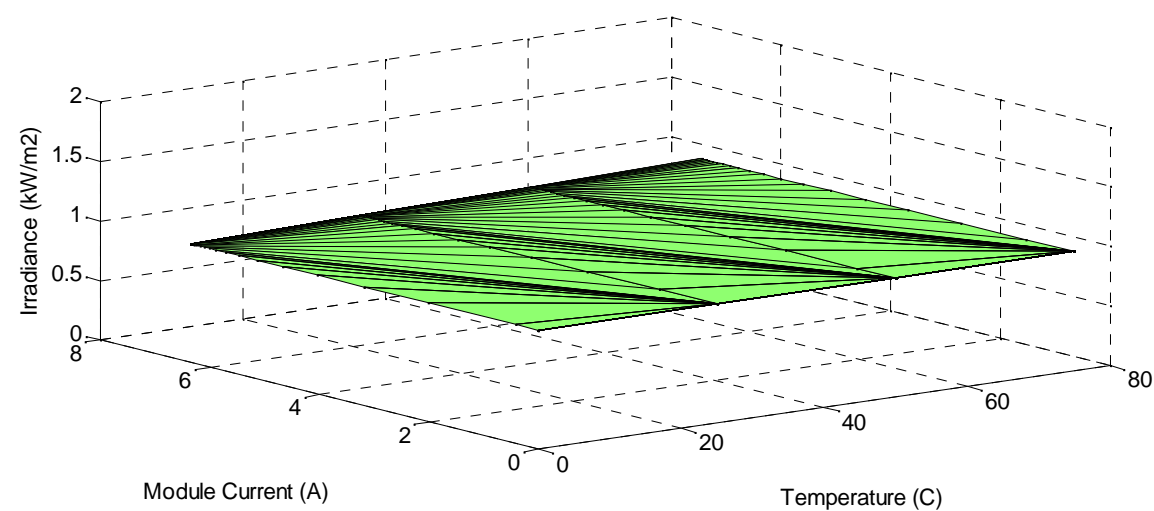

Figure (44) Current \& Temp.\& $\left(1 \mathrm{~kW} / \mathrm{m}^{2}\right)$ Irradiance

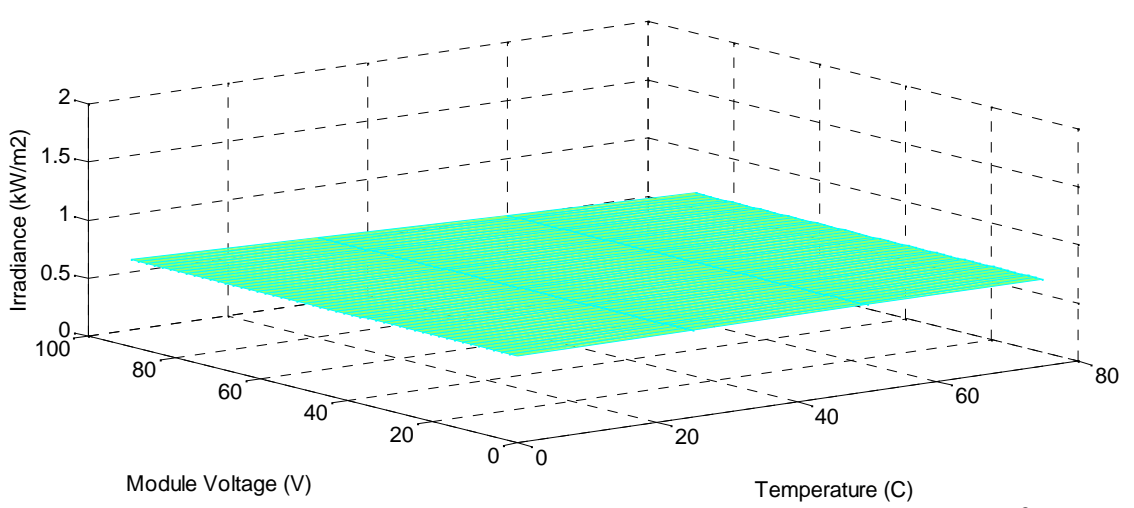

Figure (45) Voltage \& Temperature \& $\left(0.75 \mathrm{~kW} / \mathrm{m}^{2}\right)$ 


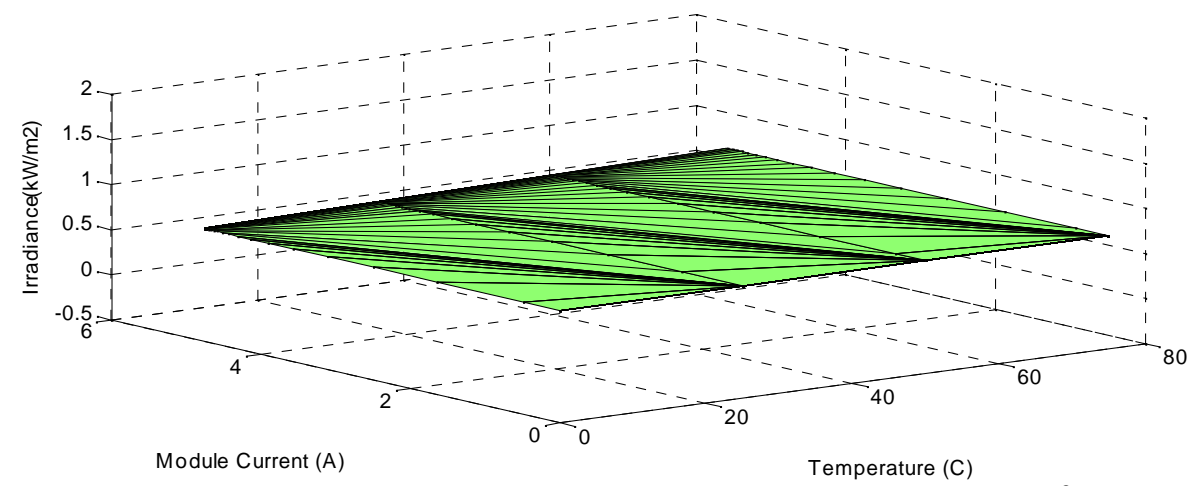

Figure (46) Current \& Temperature $\&\left(0.75 \mathrm{~kW} / \mathrm{m}^{2}\right)$

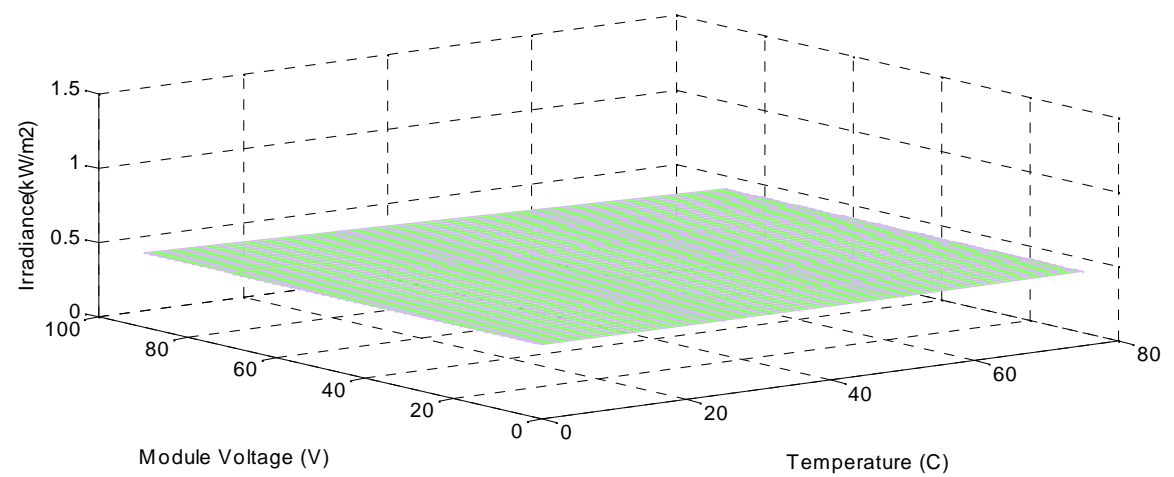

Figure (47) Voltage \& Temperature \& $\left(0.50 \mathrm{~kW} / \mathrm{m}^{2}\right)$

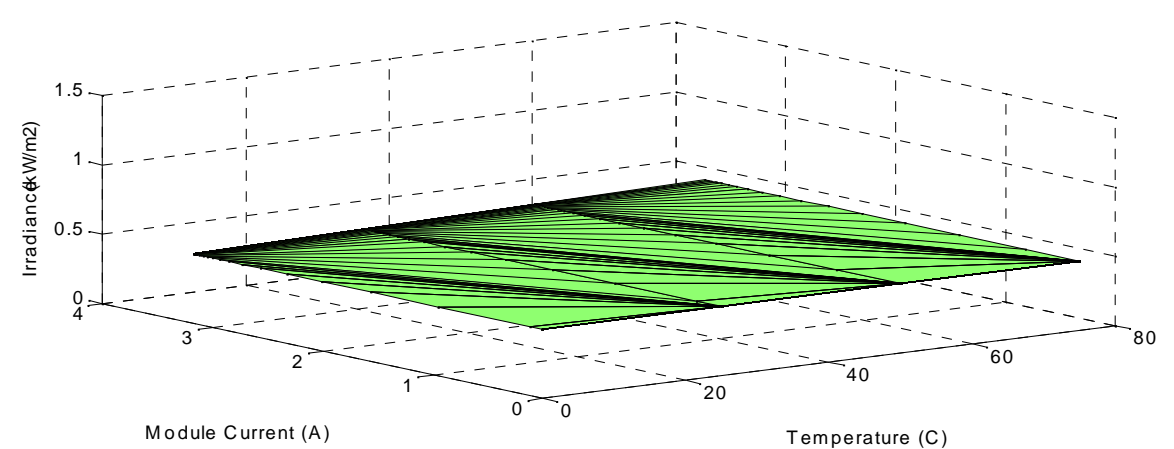

Figure (48) Current \& Temperature $\&\left(0.50 \mathrm{~kW} / \mathrm{m}^{2}\right)$

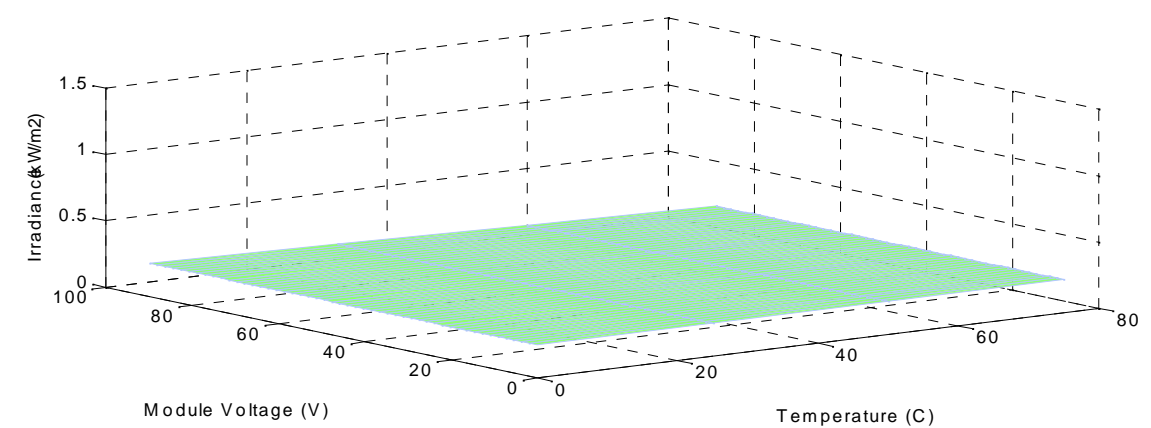

Figure (49) Voltage \& Temperature $\&\left(0.25 \mathrm{~kW} / \mathrm{m}^{2}\right)$ 


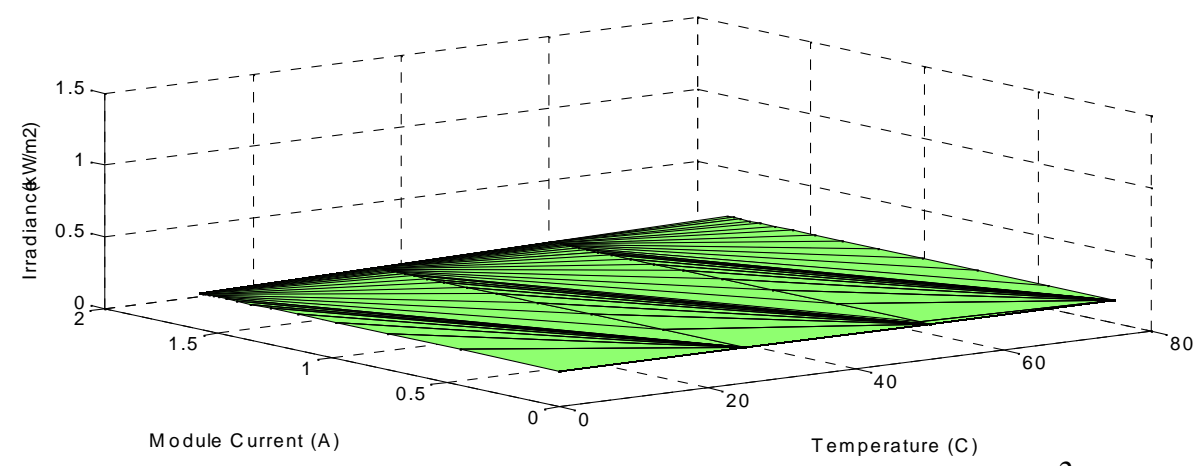

Figure (50) Current \& Temperature \& $\left(0.25 \mathrm{~kW} / \mathrm{m}^{2}\right)$

Finally, the relations of converter duty cycle, converter output voltage, and converter output current values to transfer the maximum power from the PV module to various values of resistive loads. The converter duty cycle values from these relations are taken as target or output values. These relations are presented with variable values of temperature and irradiance in figures from 51 to 62.

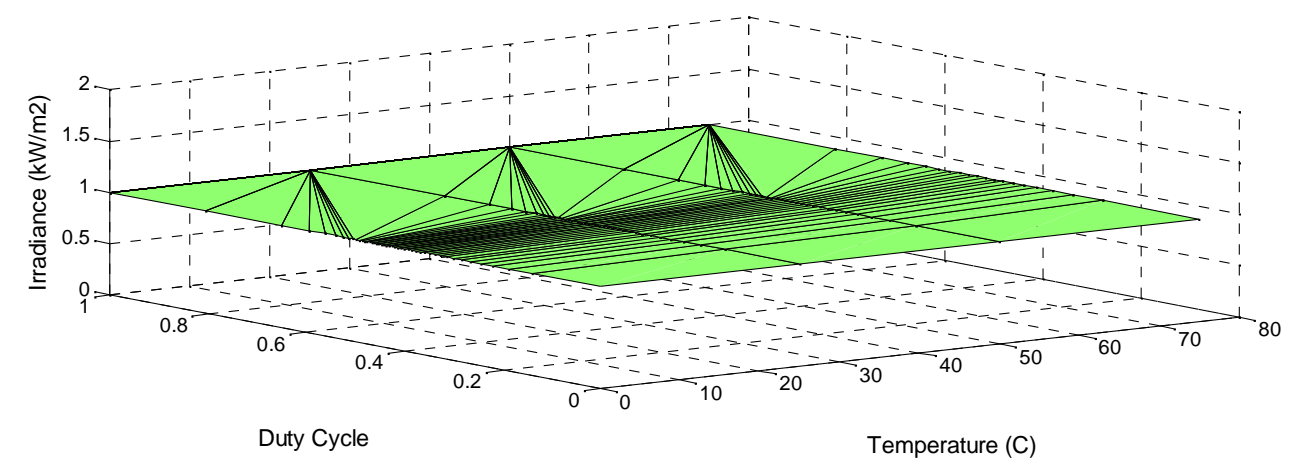

Figure (51) Converter Duty Cycle for maximum power with Temperature and $1 \mathrm{kW/m^{2 }}$ Irradiance

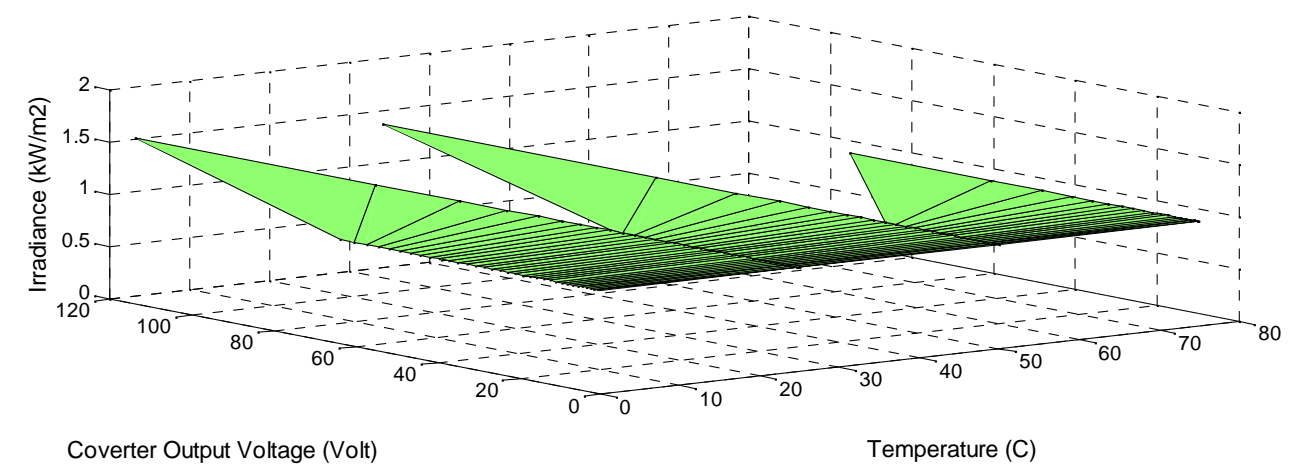

Figure (52) Converter Output Voltage for maximum power with Temperature and 1 $\mathrm{kW} / \mathrm{m}^{2}$ Irradiance 


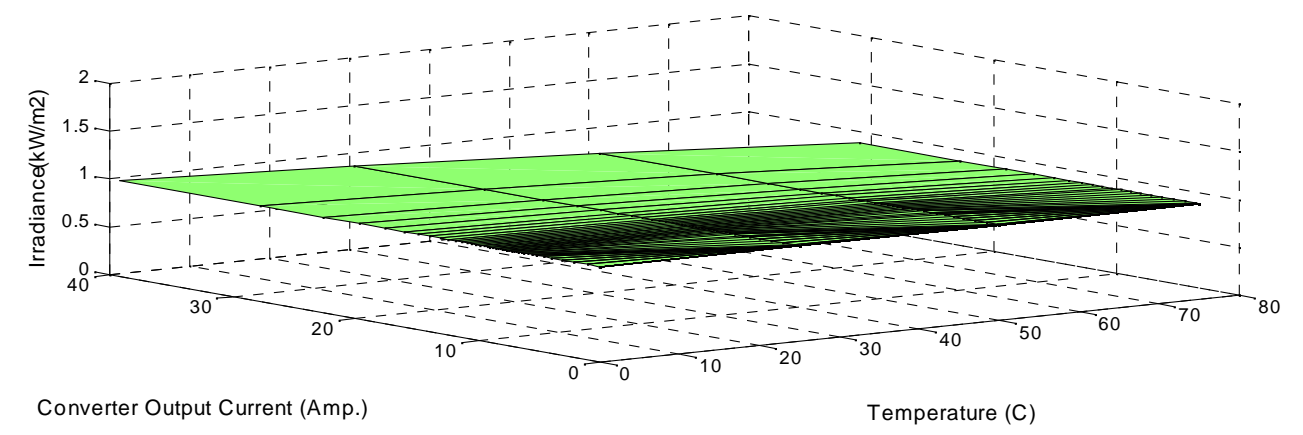

Figure (53) Converter Output Current for maximum power with Temperature and 1 $\mathrm{kW} / \mathrm{m}^{2}$ Irradiance

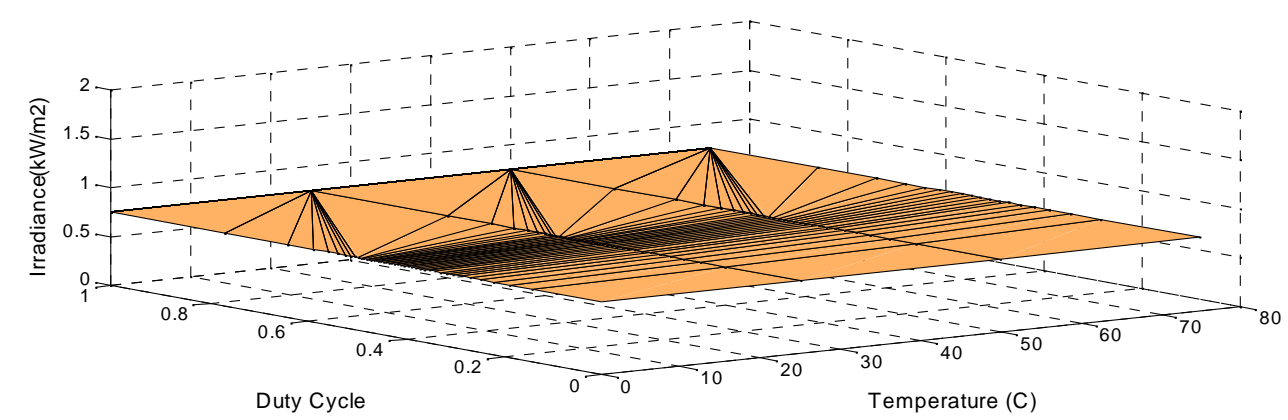

Figure (54) Converter Duty Cycle for maximum power with Temperature and 0.75 $\mathrm{kW} / \mathrm{m}^{2}$ Irradiance

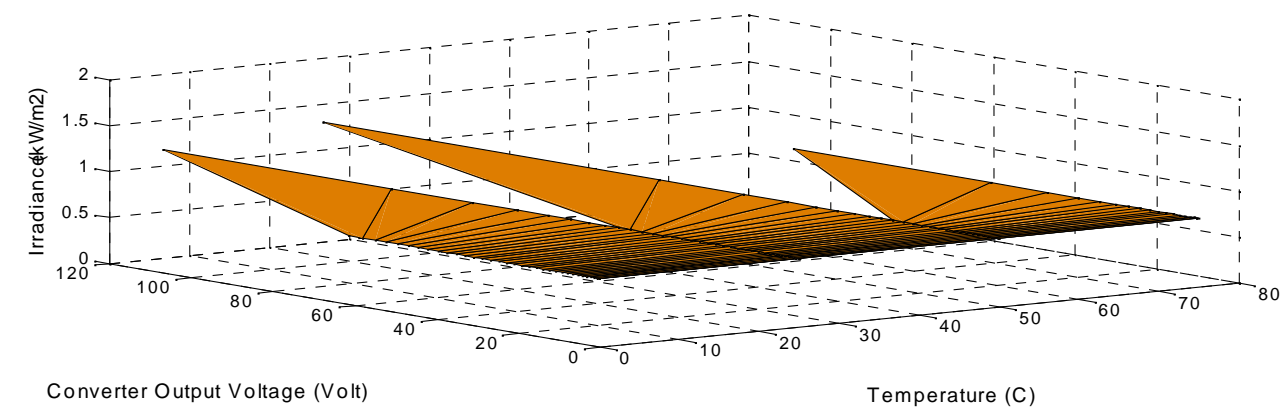

Figure (55) Converter Output Voltage for maximum power with Temperature and 0.75 $\mathrm{kW} / \mathrm{m}^{2}$ Irradiance

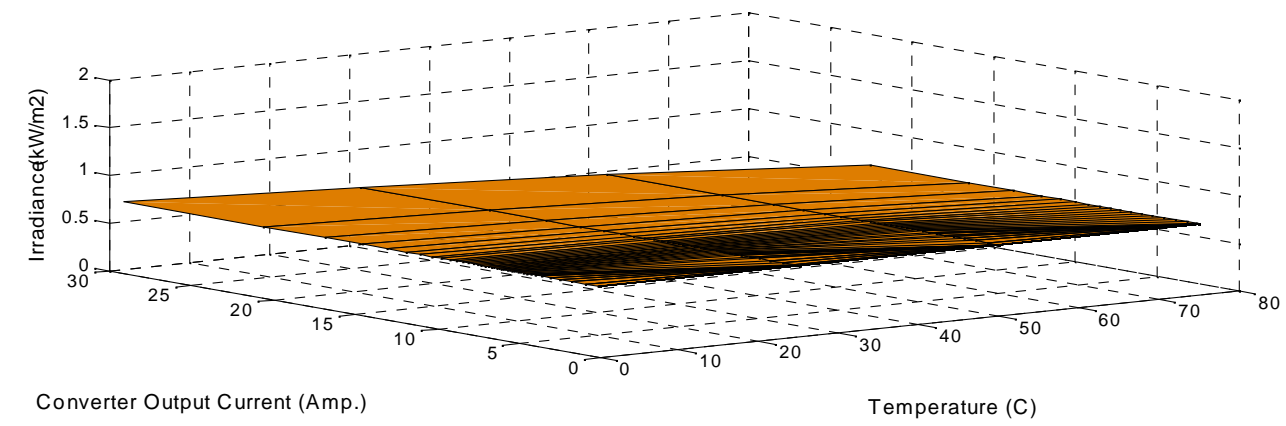

Figure (56) Converter Output Current for maximum power with Temperature and 0.75 $\mathrm{kW} / \mathrm{m}^{2}$ Irradiance 


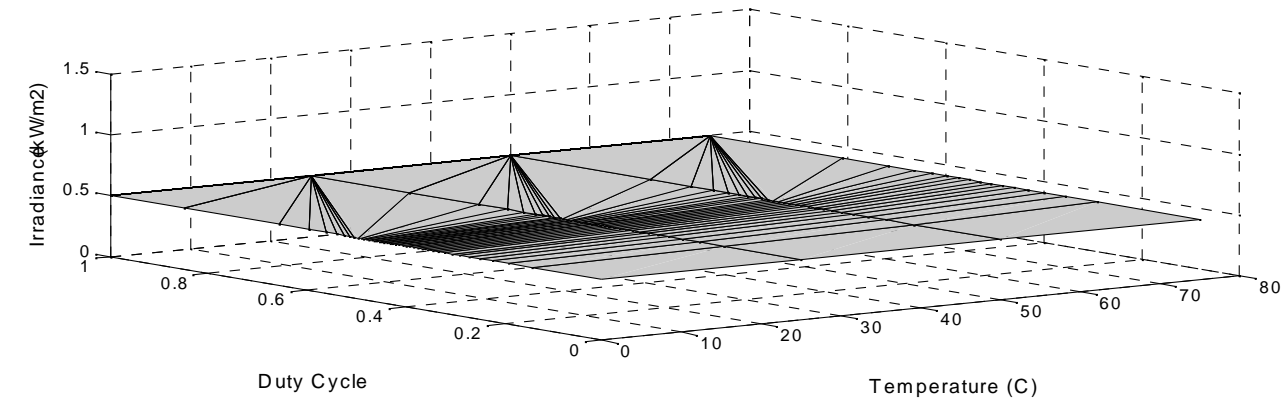

Figure (57) Converter Duty Cycle for maximum power with Temperature and 0.50 $\mathrm{kW} / \mathrm{m}^{2}$ Irradiance

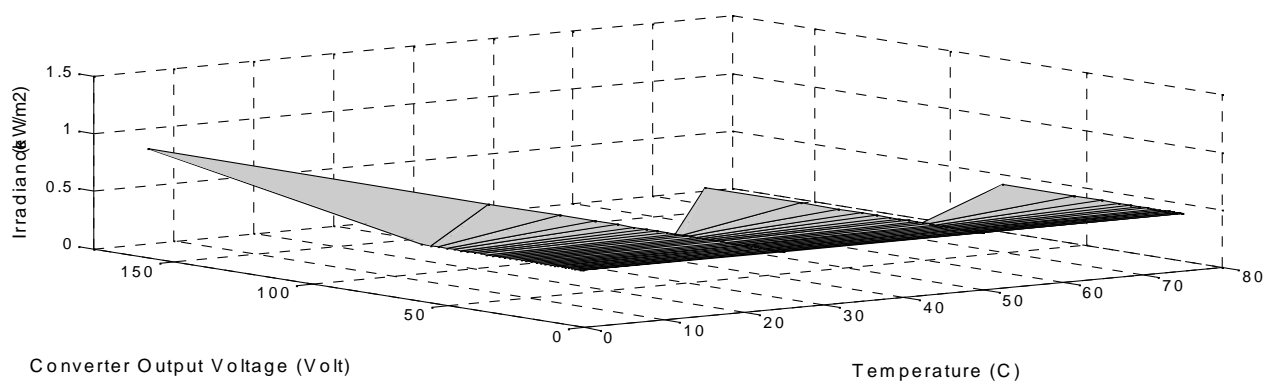

Figure (58) Converter Output Voltage for maximum power with Temperature and 0.50 $\mathrm{kW} / \mathrm{m}^{2}$ Irradiance

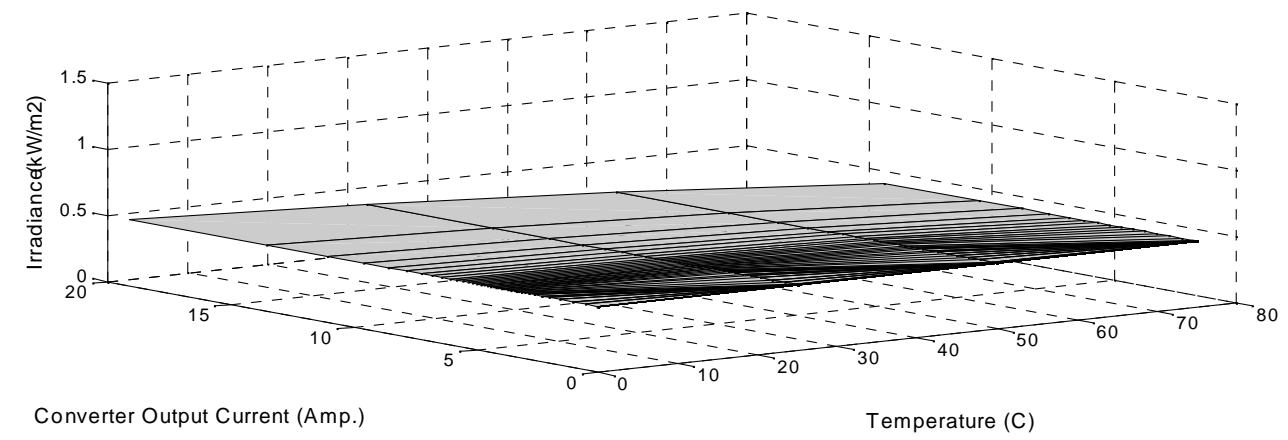

Figure (59) Converter Output Current for maximum power with Temperature and 0.50 $\mathrm{kW} / \mathrm{m}^{2}$ Irradiance

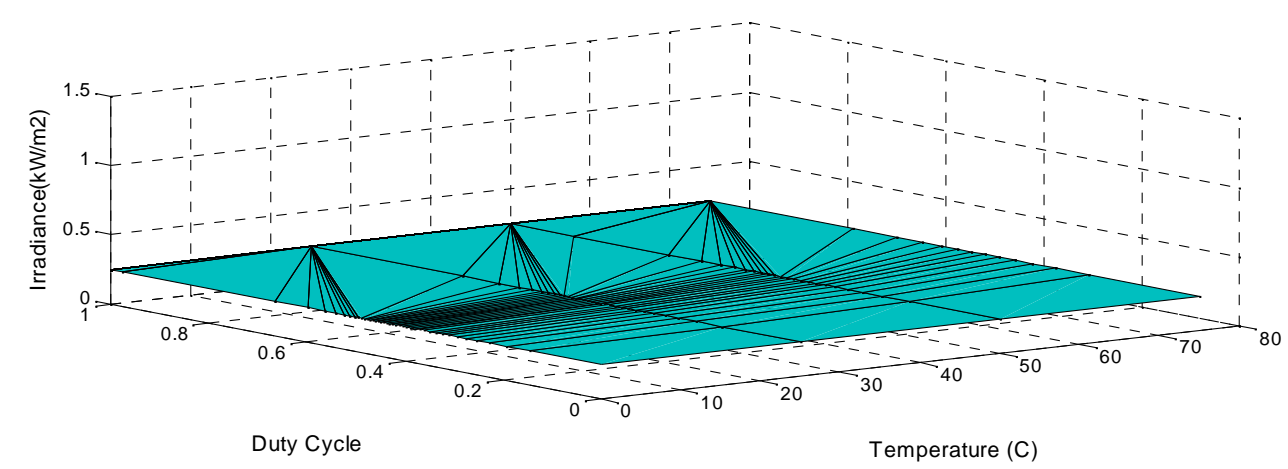

Figure (60) Converter Duty Cycle for maximum power with Temperature and 0.25 $\mathrm{kW} / \mathrm{m}^{2}$ Irradiance 


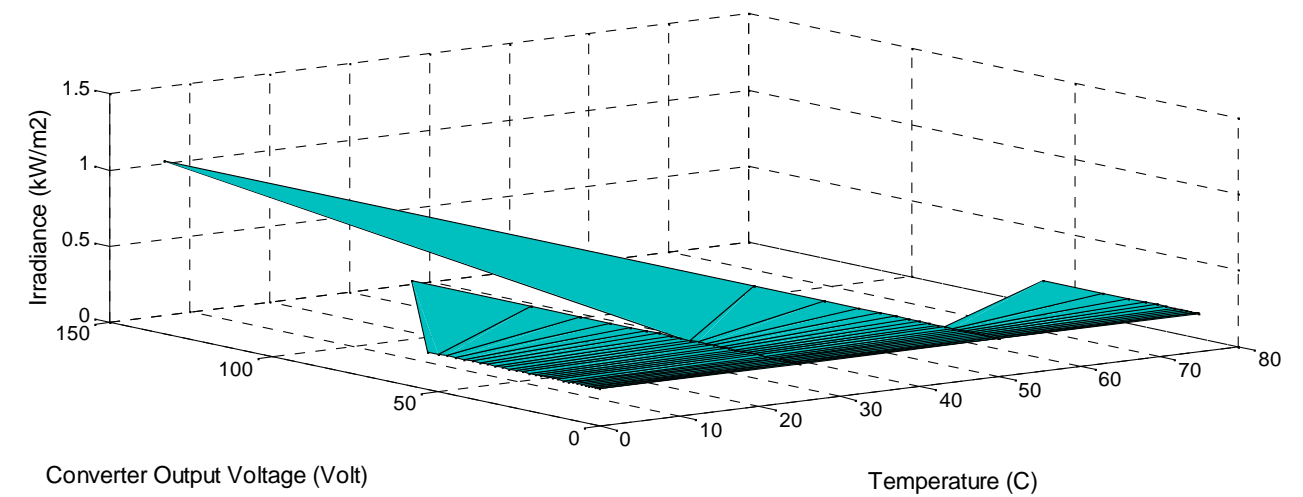

Figure (61) Converter Output Voltage for maximum power with Temperature and 0.25 $\mathrm{kW} / \mathrm{m}^{2}$ Irradiance

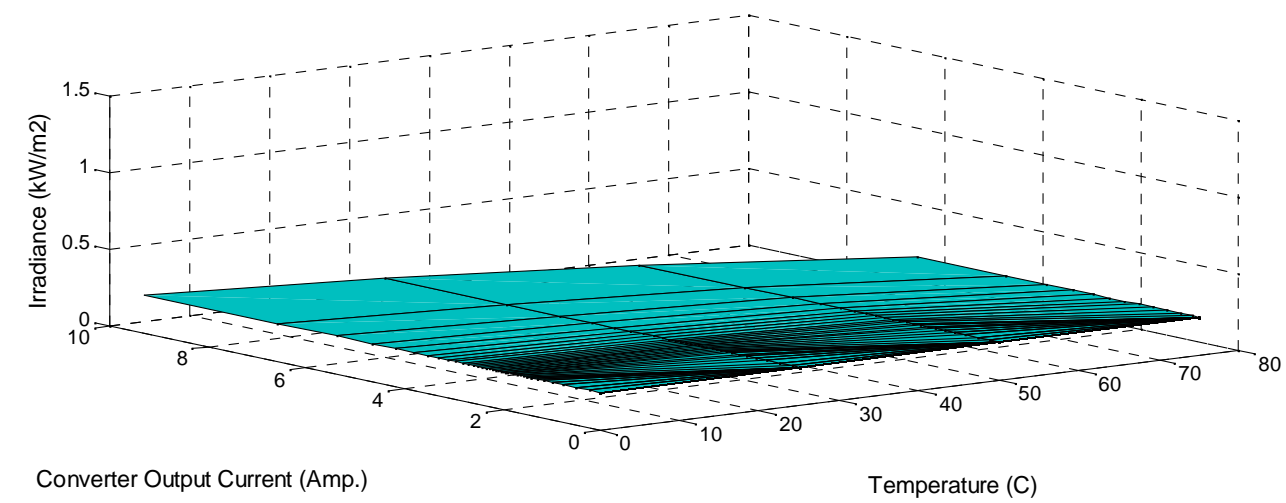

Figure (62) Converter Output Current for maximum power with Temperature and 0.25 $\mathrm{kW} / \mathrm{m}^{2}$ Irradiance

\section{Conclusion:}

This paper proposes modeling and simulation of PV Micro - Grid Distribution Generation System for Smart Grid Applications. Because, Distributed Generation (DG) offers great potential in meeting future global energy needs. PV module modeling and inverter technique reviews are presented. The mathematical PV module modeling depends on Schott ASE-300-DGF PV panel with the aid of MATLAB environment. DC / AC Inverter, Three - phase Inverters, Basic Operation of PWM Inverter, Square - wave operations of DC/AC inverter, Single - phase and Full - Bridge Converters, Three phase Converters and some MATLAB Inverters Results are introduced. Then, it proposes a PV module when coupled to a load through DC-DC Converter to supply this resistive load with the maximum power from the PV module. Some of DC-DC converters topologies are discussed in brief with concentration on Cúk and SEPIC Converters operations. After that, the mechanism of load matching is described to give the required converter duty cycle at maximum power point (MPP). Relations in 3D figures are introduced for the most probable situations for irradiance and temperature 
with the corresponding PV voltage and current. Also, 3D figures for the desired duty cycle, output voltage and current of DC-DC converter to gain the maximum power to the resistive load at various irradiance and temperature values.

\section{References:}

[1] [s.n.], ITrends in photovoltaic applications. survey report of selected iea countries between 1992 and 2006.

[2] T. Markvart and L. Castaner, Practical Handbook of Photovoltaics, Fundamentals and Applications. Elsevier, 2003.

[3] Ahluwalia, R., Wang, X., Lasher, S., Sinha, J., Yang, Y., and Sriramulu, S. "Performance of automotive fuel cell systems with nanostructured thin film catalysts." Proceedings of the 2007 Fuel Cell Seminar and Exposition, San Antonio, TX, 2007.

[4] Meimei Guo, Baijun Liu, Long Li, Chang Liu, LifengWang, Zhenhua Jiang, "Preparation of sulfonated poly(ether ether ketone)s containing amino groups/epoxy resin composite membranes and their in situ crosslinking for application in fuel cells," Journal of Power Sources 195 (2010) 11-20

[5] Tauqir A. Sherazi, Michael D. Guiver, David Kingston, Shujaat Ahmad, M. Akram Kashmiri, Xinzhong Xue, "Radiation-graf ted membranes based on polyethylene for direct methanol fuel cells," Journal of Power Sources 195 (2010) 21-29

[6] Xiu Qing Xing, KahWai Lum, Hee Joo Poh, Yan LingWu, "Optimization of assembly clamping pressure on performance of proton-exchange membrane fuel cells," Journal of Power Sources 195 (2010) 62-68

[7] K. Hussein, I. Muta, T. Hoshino, and M. Osakada, "Maximum photovoltaic power tracking: an algorithm for rapidly changing atmospheric conditions," Generation, Transmission and Distribution, IEE Proceedings-, vol. 142, pp. 59-64, Jan 1995.

[8] D. Hohm and M. Ropp, "Comparative study of maximum power point tracking algorithms using an experimental, programmable, maximum power point tracking test bed," Photovoltaic Specialists Conference, 2000. Conference Record of the Twenty-Eighth IEEE, pp. 1699-1702, 2000.

[9] D. Sera, R. Teodorescu, and P. Rodriguez, "Pv panel model based on datasheet values," Industrial Electronics, 2007. ISIE 2007. IEEE International Symposium on, pp. 2392-2396, June 2007.

10] Hohm, D. P. \& M. E. Ropp "Comparative Study of Maximum Power Point Tracking Algorithms" Progress in Photovoltaics: Research and Applications November 2002, page 47-62

11] Schott ASE-300-DGF PV panel data sheet. Source (Affordable Solar website);http://www.affordable-solar.com/admin/product_doc/Doc_pd-00-009c_ase_300_20080328114646.pdf 
12] Ali Keyhani, Mohammad N. Marwali, and Min Dai, "Integration of Green and Renewable Energy in Electric Power Systems," Wiley, January 2010

13] Masters, Gilbert M. Renewable and Efficient Electric Power Systems John Wiley \& Sons Ltd, 2004

14] Messenger, Roger \& Jerry Ventre Photovoltaic Systems Engineering 2nd Edition CRC Press, 2003

15] Castañer, Luis \& Santiago Silvestre Modelling Photovoltaic Systems, Using PSpice John Wiley \& Sons Ltd, 2002

16] Green, Martin A. Solar Cells; Operating Principles, Technology, and System Applications Prentice Hall Inc., 1982

17] Walker, Geoff R. "Evaluating MPPT converter topologies using a MATLAB PV model" Australasian Universities Power Engineering Conference, AUPEC '00,Brisbane, 2000

18] L. Philipson, Distributed and dispersed generation: addressing the spectrum of consumer needs," Power Engineering Society Summer Meeting, 2000. IEEE, vol. 3, pp. $1663\{1665,2000$.

19] G.Walker, IEvaluating mppt converter topologies using a matlab pv model," Journal of Electrical and Electronics Engineering, vol. 21, no. 1, p. 4956, 2001.

20] Adel El Shahat, "Maximum Power Point Genetic Identification Function for Photovoltaic System", International Journal of Research and Reviews in Applied Sciences, Vol. 3, Issue 3, June 2010, pp. 264 - 273.

21] Min Dai, M.N. Marwali, Jin-Woo Jung, A. Keyhani, "A Three-Phase Four-Wire Inverter Control Technique for a Single Distributed Generation Unit in Island Mode", IEEE Transactions on Power Electronics, Vol. 23, Issue 1, Jan. 2008, pp. $322-331$

22] Jin-Woo Jung and Ali Keyhani, "Control of a Fuel Cell Based Z-Source Converter", IEEE Transactions on Energy Conversion, Volume 22, No. 2, June 2007, pp. 467476

23] A.Lay-Ekuakille, G. Vendramin, A. Fedele, L. Vasanelli, A. Trotta, "PV Maximum Power Point Tracking Through Pyranometric Sensor: Modelling and Characterization", International Journal on Smart Sensing and Intelligent Systems, Vol. 1, No. 3, pp. 659-678, Sept. 2008

24] Zhu Zhen, A. Al-Mamun and Myint Phone Naing, "Control-Centric Simulator for Mechatronics Design Case Study: Gyroscopically Stabilized Single Wheel Robot", International Journal on Smart Sensing and Intelligent Systems, Vol. 2, No. 2, pp. 190-199, June 2009.

25] Shubhajit Roy Chowdhury, Dipankar Mukherjee, Hiranmay Saha, “ FPGA Based Maximum Power Point Tracker of Partially Shaded Solar Photovoltaic Arrays using Modified Adaptive Perceptive Particle Swarm Optimization", International Journal on Smart Sensing and Intelligent Systems, Vol. 2, No. 4, pp.661-675, Dec. 2009. 
26] S.C.Mukhopadhyay, " Prediction of Thermal Condition of Cage-Rotor Induction Motors under Non-Standard Supply Systems", International Journal on Smart Sensing and Intelligent Systems, Vol. 2, No. 3, pp. 381-395, Sept. 2009

27] T. Markvart and L. Castaner, Practical Handbook of Photovoltaics, Fundamentals and Applications. Elsevier, 2003.

28] K. Hussein, I. Muta, T. Hoshino, and M. Osakada, "Maximum photovoltaic power tracking: an algorithm for rapidly changing atmospheric conditions," Generation, Transmission and Distribution, IEE Proceedings-, vol. 142, pp. 59-64, Jan 1995.

29] Hohm, D. P. \& M. E. Ropp "Comparative Study of Maximum Power Point Tracking Algorithms" Progress in Photovoltaics: Research and Applications November 2002, page 47-62

30] G.Walker, IEvaluating mppt converter topologies using a matlab pv model," Journal of Electrical and Electronics Engineering, vol. 21, no. 1, p. 4956, 2001.

31] Adel El Shahat, "PV Cell Module Modeling \& ANN Simulation for Smart Grid Applications", Journal of Theoretical and Applied Information Technology, E-ISSN 1817-3195; ISSN 1992-8645; Vol. 16, No.1, June 2010, pp. 9 - 20.

32] Min Dai, M.N. Marwali, Jin-Woo Jung, A. Keyhani, "A Three-Phase Four-Wire Inverter Control Technique for a Single Distributed Generation Unit in Island Mode", IEEE Transactions on Power Electronics, Vol. 23, Issue 1, Jan. 2008, pp. $322-331$

33] Jin-Woo Jung and Ali Keyhani, "Control of a Fuel Cell Based Z-Source Converter", IEEE Transactions on Energy Conversion, Volume 22, No. 2, June 2007, pp. 467476

34] Michael D. Mulligan, Bill Broach, and Thomas H. Lee, "A Constant-Frequency Method for Improving Light-Load Efficiency in Synchronous Buck Converters", Power Electronics Letters, IEEE Volume 3, Issue 1, March 2005 Page(s): 24 - 29

35] R.D. Middlebrook and S. Cuk, "A General Unified Approach To Modelling Switching-Converter Power Stages", IEEE Power Electronics Specialists Conference, 1976 Record, pp 18-34.

36] Mikkel C. W. Høyerby, Michael A.E. Anderssen, "Envelope Tracking Power Supply with fully controlled 4th order Output Filter", Applied Power Electronics Conference and Exposition, 2006. Twenty-First Annual IEEE, 19-23 March 2006 Page(s): 8 pp. -

37] Chin Chang, "Robust Control of DC-DC Converters: The Buck Converter", Power Electronics Specialists Conference, 1995. 26th Annual IEEE Volume 2, Issue , 1822 Jun 1995 Page(s):1094 - 1097 vol.2

38] Mika Sippola and Raimo Sepponen, "DC/DC Converter technology for distributed telecom and microprocessor power systems - a literature review", Helsinki University of Technology Applied Electronics Laboratory, Series E: Electronic Publications E 3, 2002 
39] Chang, C., "Mixed Voltage/Current Mode Control of PWM Synchronous Buck Converter", Power Electronics and Motion Control Conference, 2004. IPEMC 2004. The 4th International, Publication Date: 14-16 Aug. 2004, Volume: 3, On page(s): 1136- 1139 Vol.3.

40] Mohan, Undeland, Robbins Power Electronics - Converters, Applications, and Design 3rd Edition John Wiley \& Sons Ltd, 2003

41] Rashid, Muhammad H. Power Electronics - Circuits, Devices, and Applications $3^{\text {rd }}$ Edition Pearson Education, 2004

42] Walker, Geoff R. "Evaluating MPPT converter topologies using a MATLAB PV model" Australasian Universities Power Engineering Conference, AUPEC '00,Brisbane, 2000. 